\title{
Macro- and Microstructural Alterations in Migraine and Cluster Headache
}

\author{
$\mathrm{PhD}$ Thesis
}

Nikoletta Szabó, M.D.

Clinical and Experimental Neuroscience Program,

Doctoral School of Clinical Medicine,

Faculty of Medicine, University of Szeged

Supervisor: Zsigmond Tamás Kincses, M.D., Ph.D.

Department of Neurology, Albert Szent-Györgyi Clinical Center, University of Szeged

Szeged

2014. 


\section{Table of contents}

ORIGINAL PUBLICATIONS RELATED TO THE THESIS 4

ORIGINAL PUBLICATIONS NOT DIRECTLY RELATED TO THE THESIS $\quad 4$

REVIEW PUBLICATIONS

ABBREVIATIONS

\begin{tabular}{lr} 
INTRODUCTION & 8 \\
\hline
\end{tabular}

$\begin{array}{lr}\text { MIGRAINE } & 8\end{array}$

Cluster heAdache

$\begin{array}{ll}\text { OBJECTIVES } & 12\end{array}$

METHODS 12

$\begin{array}{lr}\text { PARTICIPANTS } & 12\end{array}$

$\begin{array}{lr}\text { IMAGE ACQUISITION } & 13\end{array}$

$\begin{array}{ll}\text { IMAGE ANALYSIS } & 13\end{array}$

RESULTS

$\begin{array}{lr}\text { MIGRAINE } & 16\end{array}$

FOCAL WHITE MATTER MICROSTRUCTURE ALTERATIONS 16

SUBCORTICAL STRUCTURES' VOLUME IN MIGRAINEURS AND CONTROLS 18

THALAMIC VOLUME CHANGES ACCORDING TO THE ATTACK FREQUENCY AND DISEASE $\begin{array}{lr}\text { DURATION IN MIGRAINE } & 18\end{array}$

$\begin{array}{ll}\text { SURFACE CHANGES OF THE THALAMI IN MIGRAINEURS } & 20\end{array}$

Cluster headache $\quad 21$

$\begin{array}{ll}\text { WHITE MATTER MICROSTRUCTURAL ALTERATIONS } & 21\end{array}$

\begin{tabular}{lr} 
DISCUSSION & 22 \\
\hline
\end{tabular}

$\begin{array}{ll}\text { MigRAine } & 23\end{array}$

$\begin{array}{ll}\text { MiCROSTRUCTURAL ALTERATIONS IN MIGRAINE } & 23\end{array}$

$\begin{array}{ll}\text { THALAMIC VOLUMETRY } & 24\end{array}$

THE RELATION OF OUR FINDING TO MIGRAINE PATHOMECHANISM 25

Cluster headache 28 
CONCLUSIONS 30

ACKNOWLEDGEMENT 31

REFERENCES 32 


\section{Original publications related to the thesis:}

I. Nikoletta Szabó, Zsigmond Tamas Kincses, Árpád Párdutz, János Tajti, Délia Szok, Bernadett Tuka; András Király; Magor Babos, Erika Vörös, Giuseppe Bomboi, Francesco Orzi, László Vécsei: White matter microstructural alterations in migraine: a diffusion weighted MRI study. Pain. 2012 Mar;153(3):651-6. Epub 2012 Jan 13

\section{IF: 5.644}

II. Nikoletta Szabó, Zsigmond Tamas Kincses, Árpád Párdutz, Eszter Tóth, Gergő Csete, Délia Szok, László Vécsei: White matter disintegration in clustere headache. J Headache Pain. 2013 Jul 24;14(1):64. doi: 10.1186/1129-2377-14-64.

IF: $\mathbf{2 . 4 3}$

\section{Original publications not directly related to the thesis:}

I. Zsigmond Tamás Kincses, Nikoletta Szabó, István Valálik, Zsolt Kopniczky, Lívia Dézsi, Péter Klivényi, Mark Jenkinson, András Király, Magor Babos, Erika Vörös, Pál Barzó, László Vécsei: Target identification for stereotactic thalamotomy using diffusion tractography.

PLoS One. 2012;7(1):e29969. Epub 2012 Jan 4.

IF: 4.09

II. Dezső Németh, Cristina D. Dye, Tamás Sefcsik, Karolina Janacsek, Zsolt Túri, Zsuzsa Londe, Péter Klivényi, Zsigmond Tamás Kincses, Nikoletta Szabó, László Vécsei, Michael T. Ullman: Language deficits in pre-symptomatic Huntington's disease: evidence from Hungarian

Brain Lang. 04/2012; 121(3):248-53

IF: 3.12

III. Bernadett Tuka, Zsuzsanna Helyes, Adrienn Markovics, Teréz Bagoly, János Szolcsányi, Nikoletta Szabó, Eszter Tóth, Zsigmond Tamás Kincses, László Vécsei, János Tajti: Alteration in PACAP-38-like immunoreactivity in plasma 
during ictal and interictal periods of migraine patients

Cephalalgia 04/2013; DOI:10.1177/0333102413483931

\section{IF: 3.43}

IV. Zsigmond Tamás Kincses, Nikoletta Szabó, Eszter Tóth, Dénes Zádori, Péter Faragó, Dezső Németh, Karolina Janacsek, Magor Babos, Péter Klivényi, László Vécsei: Diffusion MRI Measured White Matter Microstructure as a Biomarker of Neurodegeneration in Preclinical Huntington's Disease

Ideggyógyászati Szemle 01/2013

\section{IF: 0.49}

V. Irena Stěpán-Buksakowska, Nikoletta Szabó, Daniel Hořínek, Eszter Tóth, Jakub Hort, Joshua Warner, Frantisek Charvát, László Vécsei, Miloslav Roček, Zsigmond Tamás Kincses: Cortical and Subcortical Atrophy in Alzheimer Disease: Parallel Atrophy of Thalamus and Hippocampus.

Alzheimer Dis Assoc Disord. 2013 Jun 6

\section{IF: 2.88}

VI. Zsigmond Tamas Kincses, Daniel Hořínek, Nikoletta Szabó, Eszter

Tóth, Gergő Csete, Irena Štěpán-Buksakowska, Jakub Hort, László

Vécsei: The Pattern of Diffusion Parameter Changes in Alzheimer's

Disease, Identified by Means of Linked Independent Component

Analysis. Journal of Alzheimer's Disease: JAD 03/2013; DOI:10.3233/JAD

$122431 \mathrm{I}$.

IF: 3.74 


\section{Review publications:}

I. Zsigmond Tamás Kincses, Nikoletta Szabó, László Vécsei: New Therapies for Treating Early Parkinson's Disease

CML-Neurology 2010; 26(3):65-79.

IF: 0.

II. Nikoletta Szabó, Zsigmond Tamás Kincses, László Vécsei: Novel Therapy in Parkinson's Disease: Adenosine A2A Receptor Antagonists

Expert Opin Drug Metab Toxicol. 2011 Apr;7(4):441-55.

IF: 3.12

Nikoletta Szabó, Zsigmond Tamás Kincses, József Toldi, László Vécsei: Altered Tryptophan Metabolism in Parkinson's Disease: A Novel Therapeutic Target

J Neurol Sci. 2011 Nov 15;310(1-2):256-60. Epub 2011 Aug 6.

IF: $\mathbf{2 . 3 2}$

\section{Scientometry}

Total impact factor: 31.264

Citation index: 35

H-index: 3 


\section{Abbreviations}

$\begin{array}{ll}\text { AD } & \text { Axial diffusivity } \\ \text { CGRP } & \text { Calcitonin gene related peptide } \\ \text { CH } & \text { Cluster headache } \\ \text { CSD } & \text { Cortical spreading depression } \\ \text { DTI } & \text { Diffusion tensor imaging } \\ \text { FA } & \text { Fractional anisotropy } \\ \text { FDT } & \text { FMRIB's Diffusion Toolbox } \\ \text { FSL } & \text { FMRIB Software Library } \\ \text { MD } & \text { Mean diffusivity } \\ \text { MMP } & \text { Metalloproteinase } \\ \text { MRI } & \text { Magnetic resonance imaging } \\ \text { PAG } & \text { Periaqueductal gray matter } \\ \text { PD } & \text { Perpendicular diffusivity } \\ \text { PET } & \text { Positron emission tomography } \\ \text { ROI } & \text { Region-of-interest } \\ \text { SPSS } & \text { Statistical Package for Social Sciences } \\ \text { TBSS } & \text { Tract based spatial statistics } \\ \text { TFCE } & \text { Threshold free cluster enhancing approach } \\ & \end{array}$




\section{Introduction}

\section{Migraine}

Migraine is the most common primary headache disorder. The disease commonly presents in the form of intense pulsing or throbbing unilateral headache. Migraine usually starts in adolescence but tends to affect predominantly people aged between 35 to 45 years. The socio-economic importance of the disease is that approximately $20 \%$ of the population suffers from disabling attacks of migraine during lifetime [1]. The pain commonly accompanied by nausea, vomiting and extreme sensibility to light, smell and sound. In one quarter of the patients the headache is preceded by transient central nervous system symptoms, mostly visual or sensory, called aura.

While environmental factors like hormonal changes, stress, changes in wake-sleep pattern or the environment, foods and drinks, medications and sensory stimuli could trigger migraine headache [2], scientific data suggest a predominantly genetic origin of the disease (see for review: $[3,4]$ ).

The underlying pathophysiological process of migraine is not entirely understood and established indicators of the disease are missing. There are evidences, that the trigeminovascular pathway and hemispheric brain structures also must have a central role in the pathomechanism, which suggest the multilevel origin of the disease. Dural perivascular trigeminal activation and the release of calcitonin gene related peptide (CGRP) and substance $\mathrm{P}[5,6]$ are involved in migraine pathomechanism and that cause neurogenic inflammation. The nociceptive information is then transmitted by the sensory neuron, residing in the trigeminal ganglion, to the trigeminal nucleus caudalis [7,8] wherefrom it is mediated to the thalamus and forth to cortical centres [9]. Most of the migraineurs also report allodynia during the attacks when non-nociceptive stimuli cause pain either in the trigeminal or extracephalic areas, which is associated with the disease duration and attack frequency [10]. This process involves the central sensitisation of the secondary and tertiary neurons of the trigeminal system [11]. Trigeminal sensitisation might arise from two distinct but not necessarily exclusive processes: 
stimulation might arise from the cortical spreading depression (CSD) [12] that stimulates trigeminal endings [13] or alternatively top-down modulation of the trigeminal system from higher-level cortical systems [14]. The altered excitability of the cerebral cortex in the interictal state seems to be fundamental in the brain's susceptibility to migraine attacks [15].

To understand the parallel steps of the pathogenesis we should examine the migraine with extended methods. Beyond the investigation of animal models (the relevance of which is limited) and laboratory tests, functional and structural imaging techniques have a crucial role to investigate in vivo alterations in migraine patient's central nervous system.

The first functional imaging studies were based on positron emission tomography (PET). PET studies found increased activity in visual cortex during migraine attack and photophobia [16,17]. Migraineurs in interictal period showed altered brain activity compared to controls $[18,19]$. In patients, hypometabolism was found in the bilateral insula, bilateral anterior and posterior cingulate cortex, left premotor and prefrontal cortex, and left primary somatosensory cortex [19]. The cerebellum and the white matter of the posterior brain-parts showed decreased glucose metabolism [18]. Moreover, based on PET studies the role of the 5HT(1A) receptors was described in the pontine raphe nuclei, the left orbitofrontal cortex, the temporal pole and the precentral gyrus [20,21]. Functional magnetic resonance imaging (fMRI) examinations confirmed the results of the PET studies. The pain-related areas showed altered activation during migraine attack [22-25] and in interictal [26-29] period.

Structural magnetic resonance imaging (MRI) studies, despite of the different methodological process, consistently revealed loss of gray matter in pain related brain regions, including the frontal cortex, temporal lobe, insula, and brainstem [3034]. Kim and coworkers described that increasing headache duration and increasing headache frequency lead to progressive reduction of the gray matter volume of the migraineurs suggesting that repeated migraine attacks may cause selective alteration to several brain regions involved in migraine pain processing [30].

White matter microstructure changes, as defined by diffusion-weighted MRI, are receiving more and more attention. Diffusion-weighted MRI is sensitive to 
diffusion of water molecules, which in the brain is largely restricted by the membranes of the cellular particles (Figure 1.). Diffusion weighted MRI is tuned to measure diffusion in certain directions and by fitting a diffusion tensor model to the measured diffusion profile, it is possible to calculate diffusion parameters that reflect the microscopic organisation of the measured volume [35].

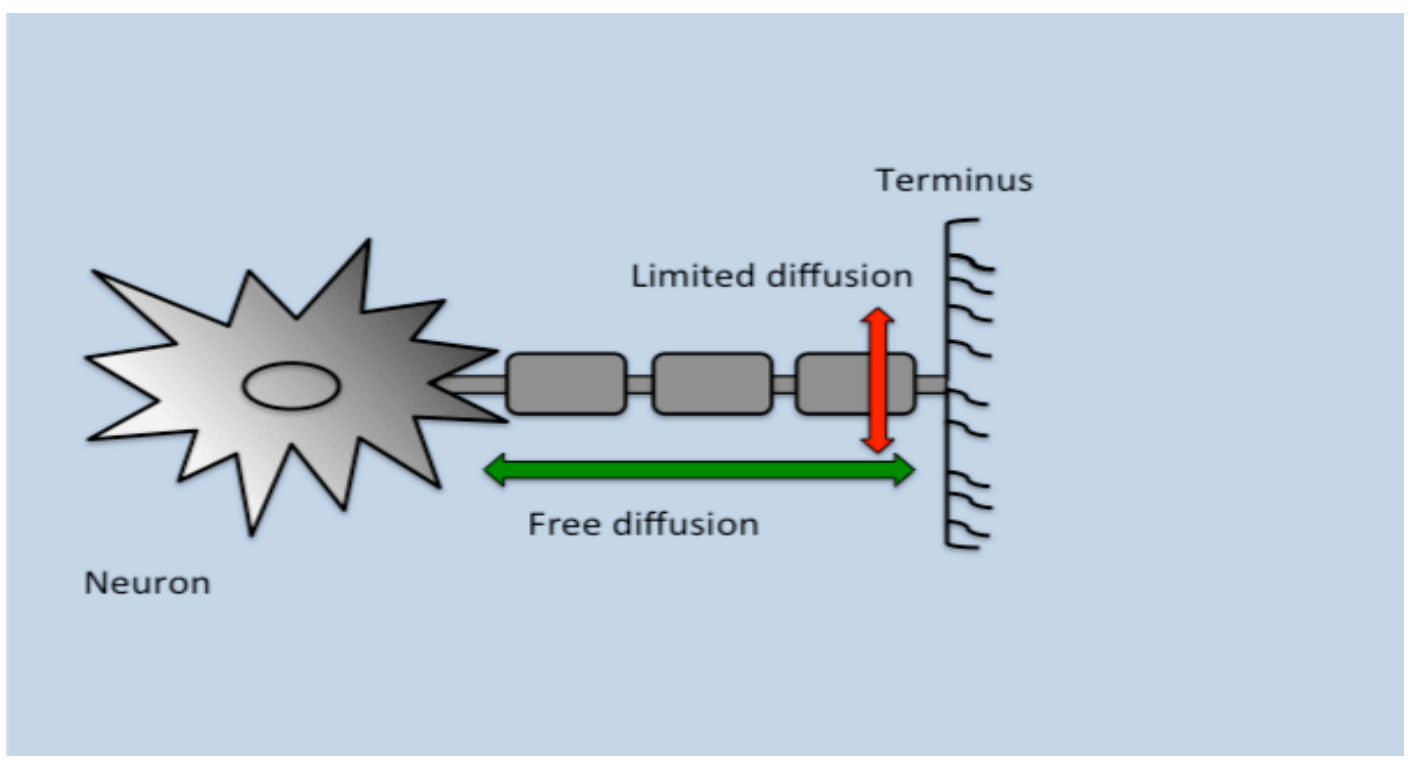

Figure 1. The restricted diffusion of water in brain tissue can be measured with diffusion tensor imaging. The movement of the water is free parallel to the axons and restricted perpendicular to the membranes. Imaging techniques allow getting information about the integrity of the white matter tracts.

A number of studies reported altered white matter microstructure in migraine with different methodological approaches. For example, lower white matter mean diffusivity (MD) and increased fractional anisotropy (FA) were found in migraine patients by means of a histogram analysis [36]. Li and co-workers, in a region-ofinterest (ROI) analysis showed reduced FA in the genu, splenium, and body of the corpus callosum [37]. Similarly, in another ROI-based analysis, Rocca and colleagues found reduced FA and higher MD in the right optic radiation of patients with aura [38]. Using a voxel-based morphometry style analysis, lower FA was described in the thalamocortical tract of migraineurs, and similar alterations were found in the trigeminothalamic tract and in the periaqueductal gray matter (PAG) of patients with and without aura, respectively [39]. By using a similar approach, Granziera and colleagues found reduced FA in the visual motion-processing network [40]. 


\section{Cluster headache}

Cluster headache $(\mathrm{CH})$, a primary headache disorder within the group of trigeminal autonomic cephalalgias, is characterised by paroxysmal hemicrania and ipsilateral craniofacial autonomic symptoms [2]. Cluster periods may last from weeks to months, usually followed by remission periods when the headache attacks stop completely. During remission, no headaches occur for months and sometimes even years. One period lasts form 6 to 12 weeks. Migraine-like symptoms can occur over an attack usually on one side. The main risk factors of $\mathrm{CH}$ are the smoking, alcohol use and positive family history. The first $\mathrm{CH}$ attack occurs between 20 and 50 years. The prevalence of the $\mathrm{CH}$ is about $0.1 \%$. Although the appearance of $\mathrm{CH}$ is much rare compared to migraine, it usually presents with a very severe headache, which causes significant disability during the attack.

The pathomechanism of $\mathrm{CH}$ is not fully understood but involves both central and peripheral mechanisms [41]. Due to the periodic appearance of the attacks, there has been numerous studies suggesting the role of the hypothalamus [42]. Positron emission tomography studies showed that the anterior cingulate cortex, the contralateral thalamus, the ipsilateral basal ganglia and both insulae were activated in $\mathrm{CH}[43,44]$. Most importantly, pain related to the emotional and autonomic response is known to be the main activator of the mentioned structures. Nevertheless, the activation of the hypothalamus seems to be a specific feature of cluster attacks [43], indicating its pivotal role in the pathogenesis and pain regulation in $\mathrm{CH}$. Since the hypothalamic activation can influence the pain-matrix [45] these findings point to the multifocal origin of the $\mathrm{CH}$, the dysfunction of the pain-matrix [41,46]. Structural MRI studies found gray as well as white matter alterations in $\mathrm{CH}$ [47] similar to those found in migraine [30,34,48]. A recent diffusion tensor imaging (DTI) study in $\mathrm{CH}$ found reduced FA in the pain matrix [49]. Contrarily, another study found no microstructural alterations (investigated FA and $\mathrm{MD}$ ) in $\mathrm{CH}$ [47]. While these results may be contradictory, imaging markers could be a powerful tool to describe disease progression and reveal important clues on the pathomechanism. 


\section{Objectives}

The aim of our study was to seek biomarkers of primary headache disorders and examine the microstructure of the white matter in migraine and cluster headache. Furthermore, thalamic morphology was examined in migraine using structural MRI methods.

\section{Methods}

\section{Participants}

Twenty-one female migraine patients and thirteen patients with episodic $\mathrm{CH}$, without any history of other neurological disorder, were chosen from the Headache Outpatient Clinic of the Department of Neurology, University of Szeged. The diagnosis was based on the criteria of the International Headache Society [50]. In order to rule out possible confounding factors, patients were all screened for depression by means of the Hamilton Depression Rating Scale [51]. Based on this, four patients were excluded from the study.

All patients underwent a clinical interview, which covered the time since the onset of headaches, frequency, quality, intensity, duration, localization of pain, provoking factors and associated symptoms. Headache-related allodynia was evaluated based on Lipton and coworkers' work [10]. The allodynia symptom checklist measures the cephalic and the extracephalic allodynia. All subjects were right-handed; none of them had a history of head injury or met the criteria of chronic headache. None of the patients had any other neurological or psychiatric diseases. None of the patients reported aura symptoms. MRI scans were acquired in the interictal period. Demographic data of the study groups listed in Table 1 and Table 2. As controls, seventeen age-matched, right-handed, healthy female individuals and sixteen controls, with no history of migraine, $\mathrm{CH}$, long-term headache or other neurological or psychiatric diseases were included in the migraine and $\mathrm{CH}$ study respectively. The study was approved by the local ethics committee (authority number: 87/2009), and all the subjects provided written consent according to the Declaration of Helsinki. 


\section{Image acquisition}

MR imaging was carried out on a 1.5T GE Signa Excite HDxt MRI scanner. During the scanning, each subject laid supine in the scanner with eyes closed and head motion was restricted with foam padding around the head, and the necessity of head immobility was explained to each subject. Scanner noise was attenuated with earplugs. 3D spoiled gradient echo (FSPGR: TE: 4.1ms, TR: 10.276ms, matrix: 256x256, FOV: 25x25cm, Flip angle: 15 degree, in-plane resolution: 1x1mm, slice thickness: $1 \mathrm{~mm}$ ) and 60 direction diffusion weighted images with 6 non-diffusionweighted reference volume (TE: 93.8ms, TR: 16000ms, matrix: 96x96, FOV: $23 \times 23 \mathrm{~cm}$, Flip angle: 90 degree, in-plane resolution: $2.4 \times 2.4 \mathrm{~mm}$ slice thickness: 2.4mm, b: 1000s/m2, NEX: 2, ASSET) were acquired for all the subjects.

\section{Image analysis}

\section{Processing of diffusion data}

Correction for eddy currents and movement artifacts by 12 DOF affine linear registration to the first non-diffusion-weighted reference image was the first step of the preprocessing [52]. Diffusion gradient directions were reoriented according to the result of eddy current correction [53]. Diffusion tensors at each voxel of the brain were fitted by an algorithm of FMRIB's Diffusion Toolbox (FDT) in FSL (v. 4.0, www.fmrib.ox.ac.uk/fsl; [54]). FA, MD, and $\mathrm{AD}(\lambda 1)$ and $\operatorname{PD}((\lambda 2+\lambda 3) / 2)$ to the principal diffusion direction were calculated for the whole brain. In $\mathrm{CH}$ study, images were mirrored to the midsaggital axis according to the side affected by the headache. In order to minimize the possible mistakes arising from misalignment of the images, we used the tract based spatial statistical (TBSS) method [55]: All subjects' FA data were aligned into a common space derived from 58 highresolution FA images of healthy subjects, using the FMRIB's Nonlinear Registration Tool, FNIRT [56] which uses a b-spline representation of the registration warp field [57]. A mean FA image was created and then thresholded at $\mathrm{FA}=0.2$, deriving a mean FA skeleton that represents the centres of all tracts common to the group. Each participant's aligned FA data were then projected onto this skeleton and the resulting data fed into voxel-wise cross-subject statistics. 
Modeling and inference using standard general linear model design set-up was accomplished using permutation-based cluster analysis (5000 permutation) [58] as implemented in FSL. The design encoded for group membership and clinical variables.

In the migraine study clusters were formed according to a defined threshold $(\mathrm{t}=$ 2.3) and corrected for multiple comparisons (across space) within the permutation framework by building up the null distribution of the maximum cluster size for each permutation $(\mathrm{p}<0.05)$. We also carried out a region of interest analysis on the white matter regions whose FA values differed significantly between groups. We tested for differences in FA, MD, longitudinal, and perpendicular diffusivity.

Connectivity of the identified differences in white matter integrity was defined by probabilistic tractography (FDT, part of FSL: www.fmrib.ox.ac.uk/fsl/fdt/) in migraineurs. We fitted a multifibre diffusion model [59] that estimates probability distributions of the direction of 1 or more fibre populations at each brain voxel. Probabilistic tractography was then performed from any brain voxel by tracing streamline samples through these probabilistic distributions on fibre direction. For tractography, we generated 5000 streamline samples from each seed voxel to build up a connectivity distribution. The number of these samples passing through each brain voxel is interpreted as proportional to the probability of connection to the seed voxel. By fitting a multifibre model to our diffusion data, we were able to follow pathways through regions of fibre crossing [59]. Cluster-masks of the TBSS analysis were used as a binary seed masks.

In $\mathrm{CH}$ study after using permutation test (5000 permutation), statistical images were thresholded by the novel threshold free cluster enhancing approach (TFCE) [60]. Similar analysis were carried out for the MD, perpendicular (PD) and axial diffusivity (AD). The diffusivity parameters were extracted from the regions indicated by the thresholded results of the TBSS analysis and these parameters were correlated with the number of cumulative headache days using Statistical Package for Social Sciences (SPSS 17 for OS X, SPSS Inc., http://www.spss.com). Laterality index was calculated for every diffusion parameter from the number of suprathreshold voxels [61]: 
$L I=\frac{N_{L}+N_{R}}{N_{L}-N_{R}}$

where $\mathrm{N}_{L}$ and $\mathrm{N}_{R}$ are the number of suprathreshold voxels in the left and right hemisphere.

\section{$\underline{\text { Volumetric analysis }}$}

Volumetric analysis of the thalamus was carried out using tools of FSL (FMRIB Software Library, http://www.fmrib.ox.ac.uk/fsl) [55]. A deformable-model-based segmentation-registration tool employing a Bayesian Appearance Model (FMRIB's Integrated Registration Segmentation Toolkit), FIRST was used, which can automatically segment the thalami [62]. For the automatic segmentation of basal ganglia, shape and intensity variations of subcortical structures were constructed from a training set of 336 images. To study the cross-subject vertex correspondence, surface meshes were obtained with a deformable model. At each vertex a sample was taken from the normalized intensities along the surface normal. Then the vertex intensity and location variation were modeled as a multivariate Gaussian distribution. Finally, maximizing the posterior probability of the shape given the observed intensities, this model was fit to new images [62]. The boundary voxels on the edge of the structure were corrected by FAST, which classifies these boundary voxels according to intensity [63]. The obtained segmentation quality was evaluated by visual inspection. Given our primary is interest of volume changes related to the sensitization of the tertial, thalamic neuron, our prior hypothesis was centered on the thalamus. The other subcortical structures were also segmented.

Volumetric comparison of the segmented thalami across groups was performed using the Statistical Package for Social Sciences (SPSS 17 for OS X, SPSS Inc., http://www.spss.com). Testing the normality of the data Shapiro-Wilk test was used and Student t-test was used to compare groups. Pearson correlation was calculated between the size of the thalami and the clinical parameters.

\section{Shape changes of the subcortical structures}

A surface mesh model was fit to the individual thalami. The corresponding vertices can be compared across groups since the number of vertices are fixed and correspond with one another across subjects. The meshes were then aligned 
(rotation and translation) to the mean surface in MNI152 space, and group comparisons of corresponding vertex locations were performed by calculating vertex-wise F statistics to investigate localized shape differences [62]. Since, this was only performed as a post-hoc localisation of the significant changes, identified with the volumetric analysis, uncorrected p-values were used.

\section{Connectivity of focal thalamic volume changes}

Probabilistic tractography was started from the descibed focal thalamic shape changes (thresholded at $\mathrm{p}<0.05$, uncorrected). The mesh surface vertices in MNI152 space were used as seed locations for tractography (FMRIB's Diffusion Toolbox, part of FSL: www.fmrib.ox.ac.uk/fsl/fdt/). We fitted a multi-fibre diffusion model [59] that estimates probability distributions on the direction of one or more fibre populations in each seed brain voxel. Probabilistic tractography was then performed from any voxel of the brain by tracing streamline samples through these probabilistic distributions on fibre direction. We generated for tractography 5000 streamline samples from each seed voxel to build up connectivity spacing. The number of these samples passing through each brain voxel is interpreted as being proportional to the probability of connection to the seed voxel. By fitting a multifibre model to our diffusion data, we were able to trace pathways through regions of fibre crossings [59]. The individual connectivity maps were registered to standard MNI152 brain. Individual tractography results were thresholded at 1000 particles (20\%), binarised and summed over subjects to represent the group level connectivity pattern.

\section{Results}

\section{Migraine}

\section{Focal white matter microstructure alterations}

As evaluated by group level voxelwise FA differences in the centre of white matter fibre bundles, the white matter microstructure was significantly changed in migraine patients as compared to controls. The differences were observed in the right frontal white matter (maximal t-score at voxel location $\mathrm{x}=25 \mathrm{~mm}, \mathrm{y}=24$ 


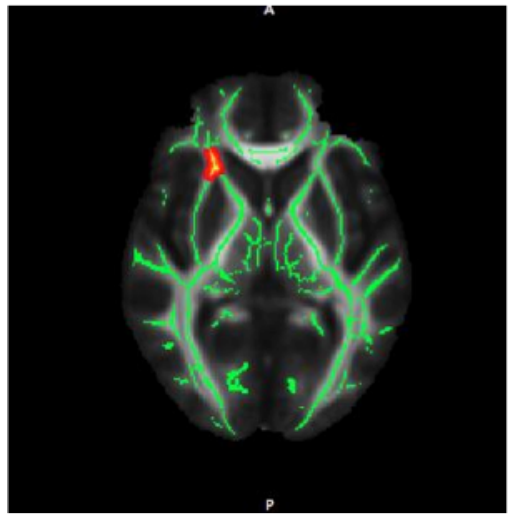

$\mathrm{mm}, \mathrm{z}=5 \mathrm{~mm}$ standard space coordinates; Figure 2.).

Figure 2. Reduced FA in the right frontal white matter in migraine patients was detected with TBSS. The mean FA skeleton is rendered in green. The t-scores are depicted in redto-yellow colours within the significant cluster.

Specifically, FA was lower (Figure 3.), while MD and PD were significantly higher in patients than in controls $(\mathrm{p}<0.0088$ and $\mathrm{p}<0.0002$, respectively, Figure 3.). AD, on the other hand, was not different between groups $(\mathrm{p}>0.101$, Figure 3.).

FA

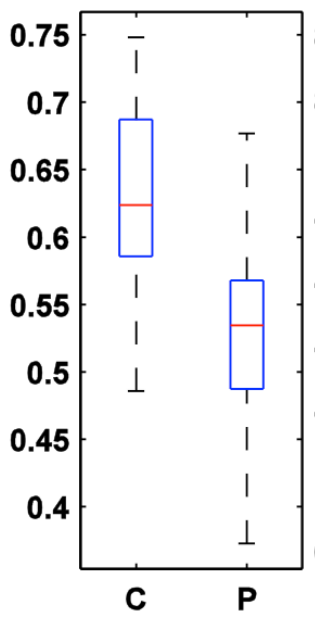

MD

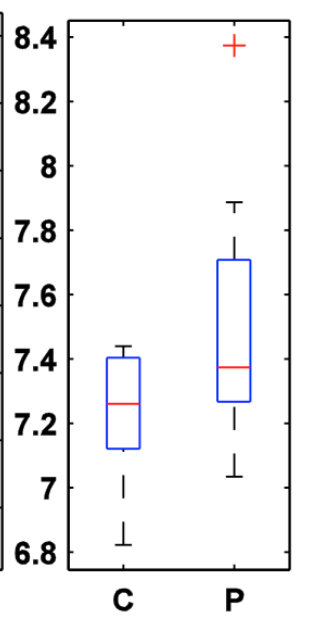

L1

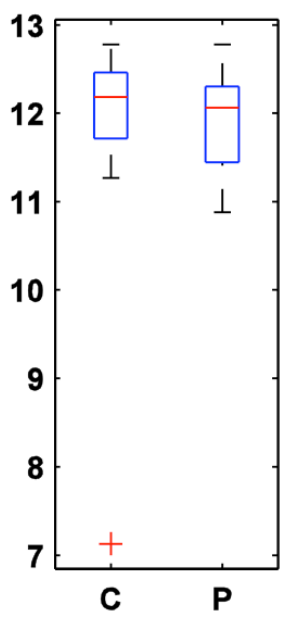

$(\mathrm{L} 2+\mathrm{L} 3) / 2$

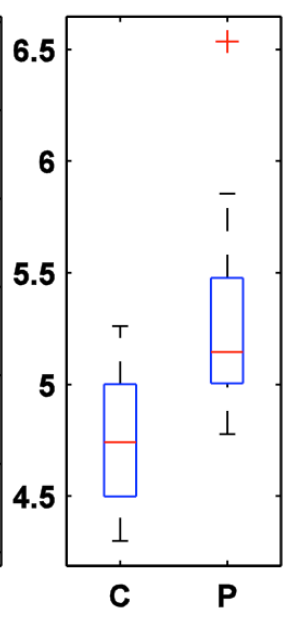

Figure 3. FA, MD, axial (L1), and perpendicular ((L2 + L3)/2) diffusivity in the cluster where reduced FA was found $(x=25 \mathrm{~mm}, \mathrm{y}=24 \mathrm{~mm}, \mathrm{z}=\mathrm{mm})$. MD was higher in migraine patients $(\mathrm{p}<$ $0.0088)$, which was explained by the increase in perpendicular diffusivity $(\mathrm{p}<0.0002)$. L1 did not differ between the groups $(\mathrm{p}>0.101)$. On the box-plot, the central mark is the mean, the boxes represent the $25 \%$ and $75 \%$ percentiles, and outliers are depicted as red crosses.

In a whole brain analysis, neither MD nor the axial/perpendicular diffusivity showed any significant difference between patients and controls. In order to further characterize the microstructural alterations found in migraine, we carried out a correlation analysis between clinical data and local FA by using an ROI approach. No correlation was found between the observed FA and disease duration or attack frequency. 


\section{Connectivity of focal FA changes in migraine}

The probabilistic tractography indicated that fibres of the right frontal white matter showing the FA alteration (identified by the TBSS analysis) were connected to the ipsilateral prefrontal cortical regions, insula, thalamus, dorsal, and ventral midbrain. Fibres proceeded in the direction of the occipital cortex through the putative inferior fronto-occipital fasciculus. Some fibres also crossed the midline through the corpus callosum (Figure 4).

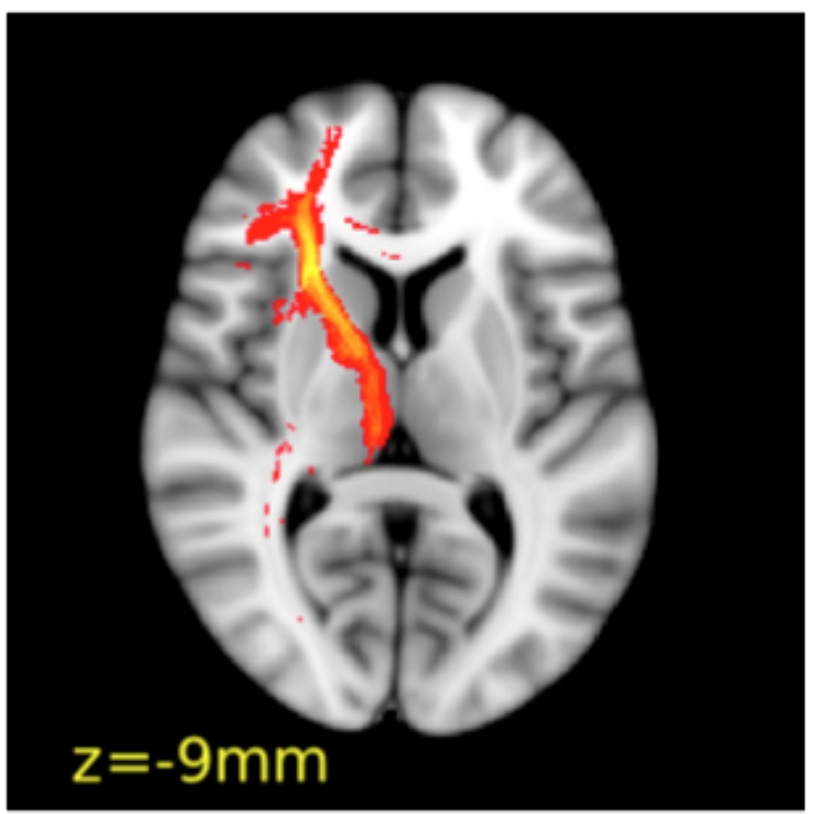

Figure 4. Connectivity of the white matter cluster showing significantly lower FA in migraine patients than in controls. The binary cluster masks were used as seed mask for each patient.

\section{Subcortical structures' volume in migraineurs and controls}

The data showed normally distribution as we tested with Shapiro-Wilk test (right thalamus: $p<0.323$; left thalamus: $p<0.529)$. The size of the left $(p<0.04)$ as well as the right $(p<0.047)$ thalami was significantly larger in patients. There was no significant difference between the size of the left and right thalamus either in case of the patients $(p<0.467)$ or the healthy subjects $(p<0.299)$. The volume of the other subcortical structures was not difference between patients and controls $(\mathrm{p}>0.05)$.

\section{The relationship of thalamic volume changes and clinical features}

We correlated the size of the thalami in migraineurs with the frequency of their attacks (the number of migraine attacks within one year, and also the total number of the attacks over the course of disease) and the duration of the disease. The 
number of attacks within one year significantly correlated with the size of the left $(\mathrm{R}=0.550 ; \mathrm{F}(1,15)=6.491 ; \mathrm{p}<0.022)$ and right thalamus $(\mathrm{R}=0.496 ; \mathrm{F}(1,15)=4.881$; $\mathrm{p}<0.043)$

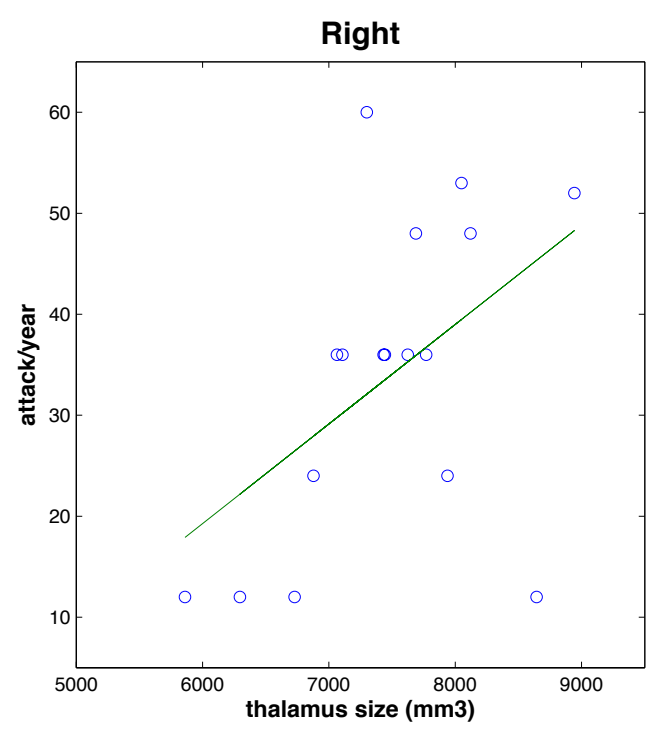

(Figure

5.).

Figure 5. Correlation of thalamic volumes with attack frequency. Correlation was significant on both side: left: $\mathrm{R}=0.550, \mathrm{p}<0.022$; right: $\mathrm{R}=0.496, \mathrm{p}<0.043$.

We found no significant correlation between the number the total attacks and the size of the thalami (right thalamus: $\mathrm{R}=0.104 ; \mathrm{F}(1,15)=0.164 ; \mathrm{p}<0.691$; left thalamus: $\mathrm{R}=0.161 ; \mathrm{F}(1,15)=0.398 ; \mathrm{p}<0.538)$. There was no significant correlation between the duration of the disease and the size of the thalami (right thalamus: $\mathrm{R}=0.176 ; \quad \mathrm{F}(1,15)=0.480 ; \mathrm{p}<0.499 ; \quad$ left thalamus: $\mathrm{R}=0.137 ; \mathrm{F}(1,15)=0.286$; $\mathrm{p}<0.601)$. Significant correlation was shown between the allodynia score of the patients and the volume of their left thalamus $(R=0.528 ; F(1,15)=5,805 ; p<0.029)$ (Figure 6.). It should be noted that this correlation was primarily driven by the highest allodynia scores. There was no significant correlation between the size of the right thalamus and the allodynia score $(\mathrm{R}=0.233 ; \mathrm{F}(1,15)=0.859 ; \mathrm{p}<0.369)$. 


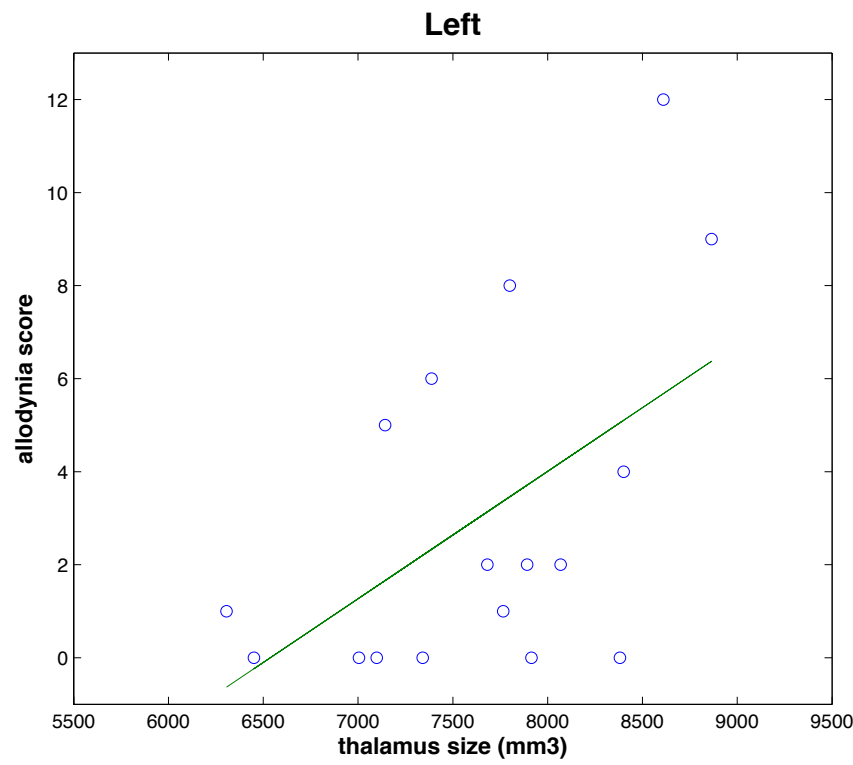

Figure 6. Correlation of the size of the left thalamus with the allodynia score. A significant correlation was found: $\mathrm{R}=0.528, \mathrm{p}<0.029$.

\section{Surface changes of the thalami in migraineurs}

The vertex-based analysis of the focal thalamic shape changes showed a local augmentation of size in the ventral region of the right thalamus in patients (Figure 7/A.). Probabilistic tractography of this enlarged area showed consistent connectivity to the dorsal brainstem. In the other direction, the highest connectivity was found to be to the premotor and prefrontal cortices (Figure 7/B.).

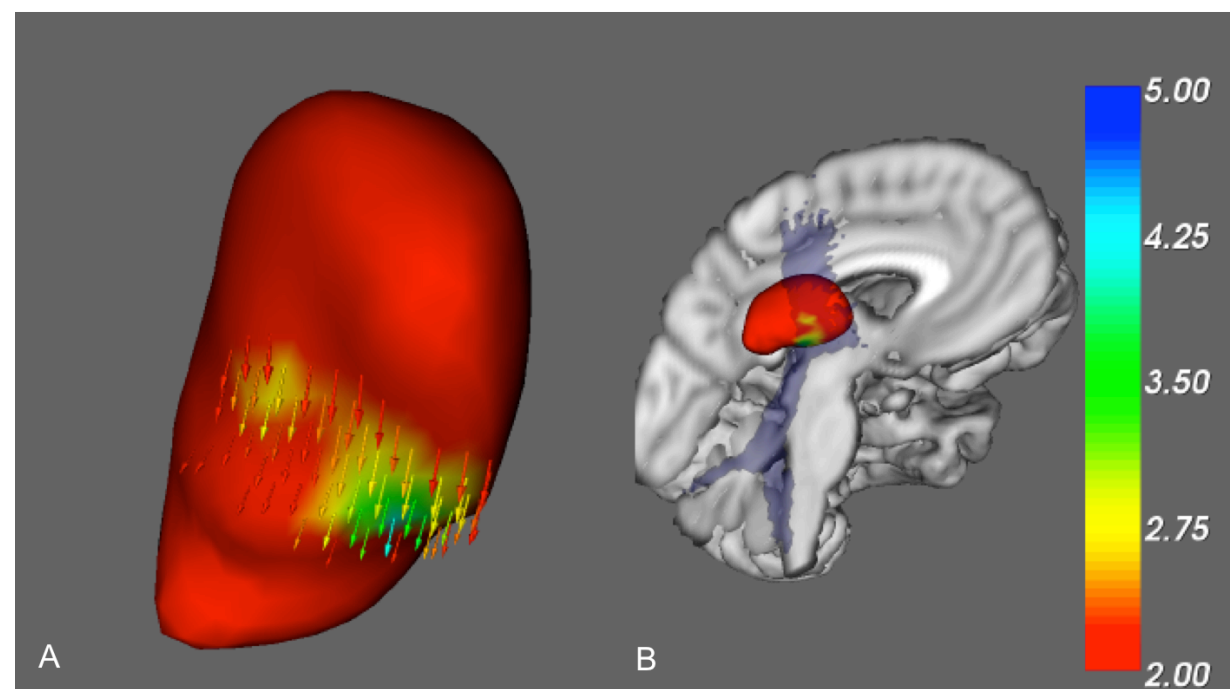

Figure 7. Focal size augmentation of the right thalamus and the connectivity of that region (A). The right thalamus is depicted from the anterior aspect and slightly below. Yellow to blue colours (colour bar on the right represent F-values) represent the location of the size augmentation in patients. The image is thresholded at $\mathrm{p}<0.05$, uncorrected. Arrows show the direction of movement of individual 
vertices across groups (B). On the 3D image the same right thalamus is depicted with the result of the probabilistic tractography in transparent blue and the connectivity of the affected thalamic region is shown. The red to yellow scale shows super-threshold connectivity values present in two patients.

\section{Cluster headache}

\section{White matter microstructural alterations}

The whole brain TBSS analysis showed decreased FA $(\mathrm{p}<0.02$, corrected for multiple comparison in the corpus callosum, bilaterally in the forceps minor and major, right corona radiata, left internal and external capsule, left cerebral peduncule, frontal portion of the left corona radiata, right parietal juxtacortical white matter, left inferior fronto-occiptal fascicle (Figure 8/A.).

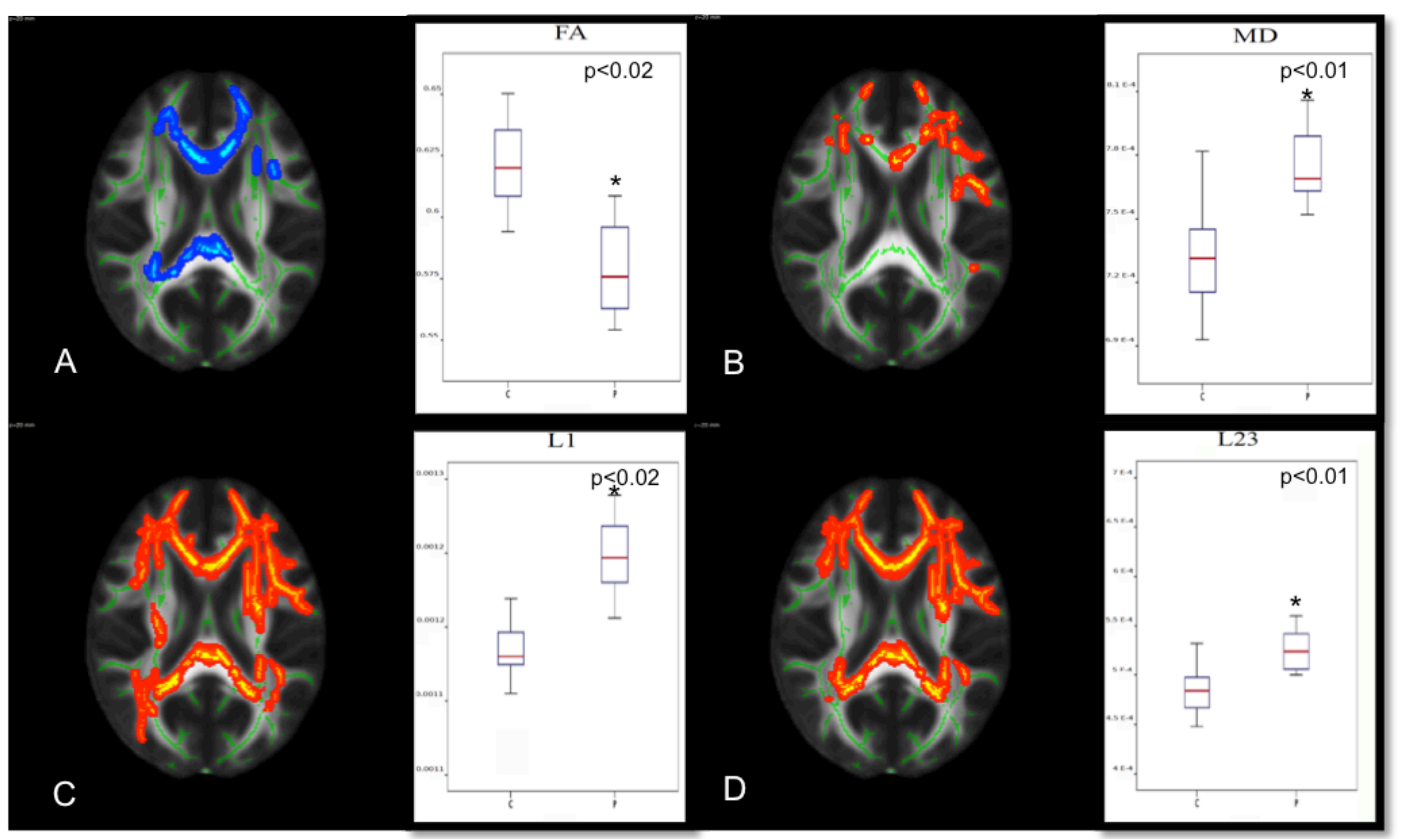

Figure 8. Diffusion parameters in cluster headache patients. Blue colours indicate reduction (A); red-to-yellow colours indicate increment $(\mathrm{B}-\mathrm{D})$ in the given diffusion parameters $(\mathrm{x}=75 \mathrm{~mm}$, $y=102 \mathrm{~mm}, z=87 \mathrm{~mm})$. The mean FA skeleton is shown in green. A thickened version of the significant cluster is used for easier visualisation (red-to-yellow or blue shades). Boxplots show the diffusion parameters of the affected area respectively.

MD was found increased ( $p<0.01$, corrected for multiple correlations) in regions where FA alterations were found, but the alterations were more extensive involving more frontal, parietal and temporal juxtacortical white matter (Figure 8/B.). Axial diffusivity was also found to be increased in widespread white matter regions $(\mathrm{p}<$ 0.02 , corrected for multiple correlations) similar to those of FA changes, but no 
significant alteration of axial diffusivity was found in the right parietal lobe in the juxtacortical white matter and the posterior corona radiate (Figure 8/C.). Augmented perpendicular diffusivity ( $\mathrm{p}<0.01$, corrected for multiple correlations) was the most extensive among the different diffusion parameters, involved essentially all major white matter fibre bundles, except the right external capsule (Figure 8/D.).

No increased FA or decreased mean, axial, or perpendicular diffusivity was detected. Laterality indices of all measured diffusion parameters showed left dominancy $\left(\mathrm{LI}_{\mathrm{FA}}: 9.8, \mathrm{LI}_{\mathrm{MD}}: 0.2, \mathrm{LI}_{\mathrm{AD}}: 0.7, \mathrm{LI}_{\mathrm{PD}}: 0.2\right)$.

There was a significant correlation between the cumulative headache days and axial diffusivity in regions showing significant differences in AD $(\mathrm{p}<0.022, \mathrm{r}: 0.626$, corrected for multiple comparisons, Figure 9.). Other diffusion parameters did not show significant correlation.

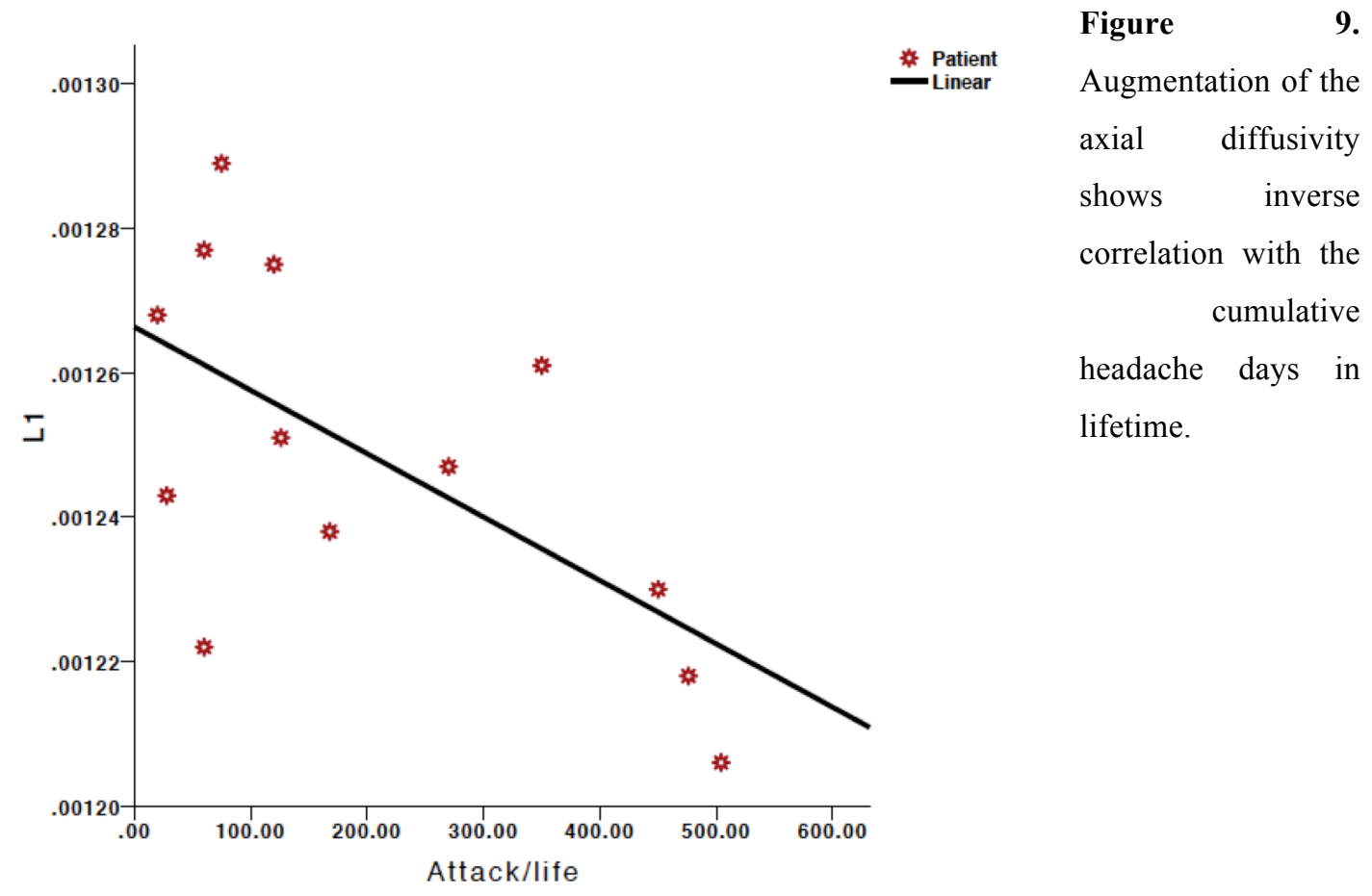

\section{Discussion}

In this thesis MRI detected structural alterations are presented in migraine and $\mathrm{CH}$ patients: (1) in migraine patients right frontal white matter microstructural 
alterations were found and (2) increased thalamic volumes were identified, which is correlated with the attack frequency and the level of allodynia, while (3) in cluster headache similar pattern of diffusion parameter alterations were detected, but more widespread in the white matter and (4) correlation was found between the disease burden and axial diffusivity.

\section{Migraine}

\section{Microstructural alterations in migraine}

Microstructural white matter alterations as measured by diffusion MRI are frequently reported in migraine. In a histogram analysis lower white matter FA and higher MD was detected in migraineurs [31]. In a region of interest analysis reduced FA was measured in the corpus callosum [37] and in the optic radiation [38]. This later was also confirmed by a voxel based morphometry style analysis [39]. Similar changes (reduced FA, increased MD) was described in the trigeminothalamic and thalamo-cortical tracts [39]. By using a similar approach, Granziera and colleagues found reduced FA in the visual motion processing network [40].

Despite the undisputed merits of these studies, our investigation overcomes some of the limitations. By investigating only the core of each fibre bundle (as defined by the local maxima of FA) we reduced the effect of the spatial variability [54]. Since this kind of data often violates the requirement of normally distributed data, the use of non-parametric permutation test further enhanced the value of our results.

Our results are in line with previous reports describing structural and functional alterations of the frontal cortex of subjects with migraine. Frontal cortical atrophy was reported in migraine patients $[32,34,64]$ and frontal cortical gray matter density reduction was correlated to T2-visible lesion load [31]. In migraineurs altered cognitive shift was correlated with the reduced frontal gray matter [65]. In a recent investigation gray matter atrophy was found in the left medial prefrontal cortex, the dorsal anterior cingulate cortex, the right occipital lobe, the cerebellum and brainstem [64]. The volume of the anterior cingulate cortex showed correlation with disease duration [64]. In migraine patients increased functional connectivity was detected between left dorsolateral prefrontal cortex, the bilateral middle temporal lobe, orbitofrontal cortex and the left anterior cingulate cortex [64]. 
However, there is a potential that alterations of the frontal lobe might not be specific to migraine. In other chronic pain syndromes gray matter loss was frequently reported in the prefrontal cortex [66], cingulate, parahippocampal gyrus, insula [67] amygdalae, hippocampi, postcentral gyri, anterior cingulate gyri, and superior frontal gyri [68]. With chronic pain conditions functional alterations are also observed in medial prefrontal cortex [69], anterior insula, cingulate cortex [70] and ventromedial prefrontal areas [71].

\section{Thalamic volumetry}

The thalamus has a cardinal role in pain perception as well as in migraine pathomechanism. It is where the second order neurons project (trigeminothalamic tract) and where the third-order neurons of the thalamocortical tract emerge. Thalamic neurons, which are responding to dural stimulation also were shown to be sensitised by ipsilateral cephalic and extracephalic chemical stimulation [72]. Migraine patients with extracephalic allodynia were shown to have a larger thalamic BOLD response to sensory stimulation than when they were free of migraine [72]. The role of the thalamus in migraine and trigeminal neuralgia was also indicated by the abnormal balance of metabolite levels, detected by MR spectroscopy, in the thalamus [73]. Thalamic activation was described during migraine attacks [74,75]. Shields and colleagues found that naratriptan (see in review: [76]) an effective medication in migraine attack, suppressed the thalamic activation evoked by the stimulation of the superior saggital sinus in the ventral posteriomedial nucleus of the thalamus [77]. Interestingly, in another trigeminal pain disorder, in temporomandibular disorder thalamic and sensory cortical gray matter enlargement was found and shown to correlate with disease duration [78,79]. In contrast, localised thalamic atrophy was detected in trigeminal neuropathy, but not in patients that were classified as having trigeminal neuralgia or temporomandibular disorders [80]. Using MR spectroscopy in the same study, reduced levels of $\mathrm{N}$-acetyl-aspartate, a marker of neuronal viability was found in the affected thalami. The difference between the direction of thalamic volume changes in trigeminal neuropathy and other pain disorder in the trigeminal territory may lie in the different pathomechanisms; peripheral events were proposed in trigeminal neuralgia and temporomandibular disorder, while the reduced volume and neural 
viability suggest central mechanisms in trigeminal neuropathy [80]. In a recent study on trigeminal neuralgia gray matter volume reduction was described in the thalamus, insula, anterior cingulate cortex, primary somatosensory and orbitofrontal cortices, secondary somatosensory cortex, cerebellum, and dorsolateral prefrontal cortex [81]. Obermann and co-workers found no influence of the disease duration on thalamic volume [81]. A further study found reduced thalamic volume (contralateral ventral postero-lateral nucleus) in limb amputees with phantom pain [82]. However, this atrophy most probably was related to the loss of sensory input than the pain, as the time since amputation was correlating with the thalamic volume and not the pain index describing the pain intensity and frequency. Contrarily, in neuropathic pain in ankylosing spondylitis increased gray matter volume in the thalamus and putamen was observed [83]. Pain characteristics were correlated with increased gray matter in the motor cortex, anterior cingulate cortex, prefrontal cortex, thalamus, and striatum and with decreased gray matter in the primary somatosensory cortex in patients [83].

\section{The relation of our finding to migraine pathomechanism}

In our view there can be alternative interpretations for the white matter alterations and the thalamic enlargement in migraine patients. Degenerative changes and maladaptive plasticity might co-occur in the disease.

(1.) In localized white matter diffusivity alteration (reduced FA) might reflect degenerative process in migraineurs. One hypothesis states that the depolarization wave progressing through the cortex has a central role in migraine pathomechanism [24]. The excessive activation might well be enough to induce in cellular damage, [14] kindle neuroinflammation and consequently cause pain [84-86]. CSD in animals upregulates the matrix metalloproteinase (MMP)-9 [87] and the activation of MMP can elicit the leakage of blood-brain barrier and lead to inflammatory response and neuronal damage [88]. Elevated MMP activity was also detected in human migraineurs [89]. Other markers of neuronal (neuron specific enolase) and glial (S100B) damage was also found in migraineurs [90]. There seems, therefore, to be some evidence for biochemical changes potentially involved in the disintegration of white matter fibre bundles that might be reflected by reduction of FA, increase of MD, and augmented perpendicular diffusivity. Similar patterns of 
DTI abnormalities are most frequently reported as a consequence of neurodegenerative processes [91,92]. Reduction of FA and AD reflect axonal loss [93-95], while increased perpendicular diffusivity seems to be a sign of demyelination $[93,94]$. The serum markers of neuronal and glial damage reported recently [90] might indicate combined damage.

In migraine patients T2 white matter lesions [96] were detected, and the lesions have been widely considered of ischemic nature [97], but not without criticism and alternative hypotheses $[98,99]$. For instance, the coexistence of antineuronal antibody suggested the inflammatory origin of the altered MRI signal [100]. Reduction of frontal gray matter volume was found to be correlated with the T2 visible lesion load [36]. Retrograde degeneration of axons passing through the macroscopic lesions was the suggested background of this correlation. In our study, however, only one patient had a right frontal $\mathrm{T} 2$ visible white matter lesion. Because of the close proximity of the lesion to our cluster of FA difference, we have repeated the analysis with the exclusion of this subject, but the results were essentially unaltered. Hence, it is likely that white matter microstructural alterations are not directly related to the $\mathrm{T} 2$ visible lesions in migraine.

(2.) As regarding the increased size of the thalami in migraine the first scenario is the thalami are genuinely larger that could kindle the pathomechanism. Longitudinal imaging studies of normal people, who later develop migraine, or genetically stratified imaging studies could be of use.

Alternatively, and more likely, the increased volume of the thalami is the result of the disease. There are evidences that repeated painful stimuli similarly to training lead to plastic changes in the brain. Gray matter morphological changes due to used-dependent plasticity have already been reported in adults [101,102]. Similar alterations were also found in the white matter with DTI [103]. As an expression of similar mechanisms, repeated pain stimuli were also reported to induce increase of gray matter density in pain processing regions, including the cingulate and the contralateral somatosensory cortex [104].

Apart from the repeated pain in migraineurs, other factors related to the pathomechanism of the disorder might also contribute to maladaptive plasticity: the altered cortical excitability [105-109] might also lead to such changes. Plastic 
changes were reported in the central nervous system of animals after induction of CSD [110,111]. A possible energy deficit suggested in migraine [112,113] might also contribute to plastic changes in the brain [114]. The cellular mechanism behind these gray matter volume changes can be suspected similar as proposed in learningrelated plastic gray matter enlargements [102], such as synaptogenesis and dendritic arborisation $[115,116]$. Furthermore, cortical spreading depression itself may induce neurogenesis in the cortex as well as in subcortical structures [117].

Another open question that the above-stated maladaptive plasticity hypothesis, however, is that in chronic pain conditions $[66,118,119,67]$ as well as in migraine [30-34], reduction rather than increase of gray matter size or density has been reported, as seen, for example, in learning [102]. Similarly, white matter alterations due to use-dependent plasticity-like processes were expected to appear in the form of increased FA, as it was reported recently [120]. Explanation of such controversy may lie in a lack of noxious stimulus in chronic pain [121], chronification of the pain condition, compensatory mechanisms [122] or affective components [123], and personality traits related to migraine [124].

Another aspect of our findings that has to be considered is the integration of the thalamic enlargement and the prefrontal white matter alteration in the pain related functional networks. Hadjipavlou and co-workers described the pain network that contains prefrontal cortex, periaqueductal gray and cuneiform nucleus, amygdala, thalamus and hypothalamus, and rostroventral medulla [125]. Our tractography findings are in line with this study; accurately the prefrontal white matter lesion and the enlarged thalamic region are connected to the above-mentioned structures.

The vertex analysis showed that the ventral surface of the thalamus was enlarged in patients. The probabilistic tractography showed that this ventral aspect of the thalamus is the area connected to brainstem structures. These structures cannot be unanimously identified with the current resolution, but might connect thalamus to the PAG or could possibly be the fibres from the putative trigemino-thalamic pathway. Regarding the pathomechanism of migraine each of these pathways could have crucial importance $[36,113]$. However it has to be pointed out that earlier investigations described the connectivity of PAG to the mediodorsal thalamus [126], rather than to the thalamic region in our analysis. In the other direction the 
enlarged thalamic region is connected, with the highest probability, to the frontal cortex. Together with the above-mentioned results it must be emphasized that the role of these regions should not be evaluated individually, but must be seen as part of a network, the parts of which are heavily interconnected [127,125].

We found thalamic volume being related to attack frequency and allodynia reported by the patients. Allodynia (an abnormal sensory state in which normally inoxious stimuli sensed as painful) is a frequently reported feature of migraine [128] and thought to be a sign of neuronal sensitisation. The first order neurons of the trigemino-vascular pathway are in the trigeminal ganglion, which innervate the dural sinuses and project to the spinal trigeminal nucleus. The second order neurons process information from the dural vessels and from both the skin and deep tissue of the periorbital region. The sensitisation of the first order neuron is thought to be related to the throbbing nature of the pain [129]. The sensitisation of the second order neurons is thought to be related to the allodynia around the eye on the affected side and the referred pain [11]. The third order neurons in the thalamus that receive projections from the ipsi- and contralateral second order trigeminal neurons and from all other level of the spinal cord, process multimodal information from the affected and contralateral side of the head as well as from extracephalic regions [130]. In a recent parallel rodent electrophysiological and human fMRI investigation extracranial allodynia was associated with the sensitisation of these third order neurons [72]. Furthermore, reduced fractional anisotropy was found in the thalamocortical tracts in migraineurs [39]. It would be tempting to relate the thalamic enlargement to the appearance of extracranial allodynia in our study group also, but almost all the patients having allodynia also reported that as being extracranial, and therefore we do not have appropriate statistical power.

\section{Cluster headache}

In the literature there are contradictory results on the diffusion alterations in cluster headache, despite using the same analysis approach as in our study. In a DTI study, Teepker and colleagues described reduction of FA in several brain regions, but no other diffusion parameters were investigated [49]. The extent of the FA alterations was much smaller than in our study. Another investigation on $\mathrm{CH}$ patients found no 
alteration of FA or MD with similar analytical method [47]. One possible reason why we found more widespread changes than in previous studies could be because of the high angular resolution DTI acquisition, what we have used in our study, thereby providing a higher signal to noise ratio [131].

Correlation between the alteration of diffusion parameters and tissue microstructure is not yet entirely clear. However, the increment of mean and perpendicular diffusivity, which was the most prominent finding of our study, is most probably a sign of increased distances between membranes. This mostly relates to demyelination [94,93], but combined axon and myelin loss may also cause a complex change of diffusion parameters [132]. The increased inter-membrane distance [133] may also cause increased perpendicular diffusivity. One could speculate that the changes in the extracellular space might be related to the sterile inflammation proposed in $\mathrm{CH}$ [134]. However recent SPECT study did not find evidence of increased number of intracranial white blood cells in $\mathrm{CH}$ [135].

It was previously suggested that the lack of correlation of diffusion abnormalities with attack frequency or disease duration point to a phenotypic biomarker of the disease, reflecting a congenital condition rather than a process related to disease progression over time [47]. However in our current investigation we found a negative correlation between the axial diffusivity and the cumulative headache days. This interesting finding can be explained by observations showing that early stage of axon damage is associated with reduced axial diffusivity $[95,94,93,132,136]$. However later, the axial diffusivity will pseudo-normalise again as the axon and myelin debris gradually cleared [137,138]. This mechanism could potentially explain our findings, nevertheless it should be emphasized that none of the DTI indices are a direct measurement of specific white matter compartments [139], hence no direct relation can be established between our results and the pathomechanism of $\mathrm{CH}$.

Functional and structural studies on cluster headache found activation and gray matter changes in the contralateral side of the pain [140-143]. Similar lateralisation of the white matter microstructural alterations were found in our investigation. Importantly, this finding point toward a mechanism different from vasodilatation of the intracranial arteries, since that is reported ipsilateral to the pain [144]. 


\section{Limitations}

Our studies are certainly not without limitation. Longitudinal studies are needed in order to reveal if the identified white matter microstructural changes are permanent. Furthermore, it would be important to know if the structural alterations have influence on brain function other than the experienced pain. Earlier studies showed that migraine and $\mathrm{CH}$ patients have a decline of memory processing during headache attack, but not between attacks and no progressive cognitive decline was detected $[145,146]$. While our results are solely structural in nature, given the strong coupling between structure and function in the brain, functional correlates also have to be considered. Our results can be paralleled by recent experiments showing altered resting state fMRI activity in migraine and $\mathrm{CH}$ patients [46,147-149]. Furthermore, investigation of the correlation between these microstructural alterations and molecular markers is imperative to get in depth understanding of the pathogenetic relevance of our findings.

\section{Conclusions}

Our findings raise the possibility that diffusion imaging and thalamic volumetry in research settings could be a possible biomarker of the primary headache disorders. The pattern of diffusion parameter changes, what we found in $\mathrm{CH}$ is similar to what we have described with identical methods in migraine, but the changes in $\mathrm{CH}$ are more extensive. However, specificity to migraine as opposed to other chronic pain conditions has to be investigated. While thalamic enlargement seems to be a clue to the pathogenesis of migraine chronification, further investigations into the different phases of the disease would help to elucidate the importance of our findings. 


\section{Acknowledgement}

I would never have been able to finish my dissertation without the guidance of my committee members, help from friends, and support from my family.

I would like to thanks to Professor László Vécsei giving opportunity working in the Department of Neurology and supporting my work.

I would like to express my deepest gratitude to my advisor, Dr. Zsigmond Tamás Kincses, for his excellent guidance, patience, caring.

Special thanks goes to Dr. Árpád Párdutz, who as a good tutor and friend, was always willing to help and give his best suggestions in the science and in the clinical work as well.

Many thanks to Dr. Eszter Tóth, Bernadett Tuka, Dr. Gergő Csete, Dr. András Király, Dr. Péter Faragó, Annamária Fejes-Szabó, Rita Török, for their practical help and providing me with an excellent atmosphere for doing research. My research would not have been possible without their helps.

I would like to thank to Dr. János Tajti, Dr. Délia Szok, Dr. Péter Klivényi and every worker of the Neurology Clinic for their constant help and assistance.

I would also like to thank my parents, my brother, my grandparents and my sisterin-low. They were always supporting me and encouraging me with their best wishes. Finally, I would like to thank my friends at home and in Szeged. They were always there cheering me up and stood by me through the good times and bad. 


\section{References}

1. Carson AP, Rose KM, Sanford CP, Ephross SA, Stang PE, Hunt KJ, Brown CA, Szklo M (2004) Lifetime prevalence of migraine and other headaches lasting 4 or more hours: the Atherosclerosis Risk in Communities (ARIC) study. Headache 44 (1):20-28. doi:10.1111/j.1526-4610.2004.04005.x

2. Lipton RB, Bigal ME, Steiner TJ, Silberstein SD, Olesen J (2004) Classification of primary headaches. Neurology 63 (3):427-435

3. Silberstein S, Dodick D (2013) Migraine genetics - a review: part I. Headache 53 (8):1207-1217. doi:10.1111/head.12156

4. Silberstein SD, Dodick DW (2013) Migraine Genetics: Part II. Headache 53 (8):1218-1229. doi:10.1111/head.12169

5. Villalon CM, Olesen J (2009) The role of CGRP in the pathophysiology of migraine and efficacy of CGRP receptor antagonists as acute antimigraine drugs. $\begin{array}{lllll}\text { Pharmacology } \quad \& \quad & \text { therapeutics } & 124 & \text { (3):309-323. }\end{array}$ doi:10.1016/j.pharmthera.2009.09.003

6. Olesen J (2011) Calcitonin gene-related peptide (CGRP) in migraine. Cephalalgia 31 (4):510. doi:10.1177/0333102410388438

7. Moskowitz MA (1984) The neurobiology of vascular head pain. Ann Neurol 16 (2):157-168. doi:10.1002/ana.410160202

8. Goadsby PJ, Lipton RB, Ferrari MD (2002) Migraine--current understanding and treatment. N Engl J Med 346 (4):257-270. doi:10.1056/NEJMra010917

9. Noseda R, Jakubowski M, Kainz V, Borsook D, Burstein R (2011) Cortical projections of functionally identified thalamic trigeminovascular neurons: implications for migraine headache and its associated symptoms. The Journal of neuroscience : the official journal of the Society for Neuroscience 31 (40):1420414217. doi:10.1523/JNEUROSCI.3285-11.2011

10. Lipton RB, Bigal ME, Ashina S, Burstein R, Silberstein S, Reed ML, Serrano D, Stewart WF, American Migraine Prevalence Prevention Advisory G (2008) Cutaneous allodynia in the migraine population. Ann Neurol 63 (2):148-158. doi:10.1002/ana.21211 
11. Burstein R, Cutrer MF, Yarnitsky D (2000) The development of cutaneous allodynia during a migraine attack clinical evidence for the sequential recruitment of spinal and supraspinal nociceptive neurons in migraine. Brain 123 ( Pt 8):17031709

12. Leo AAP (1944) Pial circulation and spreading depression of activity in the cerebral cortex. Journal of Neurophysiolog 7:391-396

13. Bolay H, Reuter U, Dunn AK, Huang Z, Boas DA, Moskowitz MA (2002) Intrinsic brain activity triggers trigeminal meningeal afferents in a migraine model. Nature medicine 8 (2):136-142. doi:10.1038/nm0202-136

14. Moskowitz MA (2007) Pathophysiology of headache--past and present. Headache 47 Suppl 1:S58-63. doi:10.1111/j.1526-4610.2007.00678.x

15. Lang E, Kaltenhauser M, Neundorfer B, Seidler S (2004) Hyperexcitability of the primary somatosensory cortex in migraine--a magnetoencephalographic study. Brain 127 (Pt 11):2459-2469. doi:10.1093/brain/awh295

16. Boulloche N, Denuelle M, Payoux P, Fabre N, Trotter Y, Geraud G (2010) Photophobia in migraine: an interictal PET study of cortical hyperexcitability and its modulation by pain. J Neurol Neurosurg Psychiatry 81 (9):978-984. doi:10.1136/jnnp.2009.190223

17. Denuelle M, Boulloche N, Payoux P, Fabre N, Trotter Y, Geraud G (2011) A PET study of photophobia during spontaneous migraine attacks. Neurology 76 (3):213-218. doi:10.1212/WNL.0b013e3182074a57

18. Kassab M, Bakhtar O, Wack D, Bednarczyk E (2009) Resting brain glucose uptake in headache-free migraineurs. Headache 49 (1):90-97. doi:10.1111/j.15264610.2008.01206.x

19. Kim JH, Kim S, Suh SI, Koh SB, Park KW, Oh K (2010) Interictal metabolic changes in episodic migraine: a voxel-based FDG-PET study. Cephalalgia 30 (1):53-61. doi:10.1111/j.1468-2982.2009.01890.x

20. Demarquay G, Lothe A, Royet JP, Costes N, Mick G, Mauguiere F, Ryvlin P (2011) Brainstem changes in 5-HT1A receptor availability during migraine attack. Cephalalgia 31 (1):84-94. doi:10.1177/0333102410385581 
21. Lothe A, Merlet I, Demarquay G, Costes N, Ryvlin P, Mauguiere F (2008) Interictal brain 5-HT1A receptors binding in migraine without aura: a 18F-MPPFPET study. Cephalalgia 28 (12):1282-1291. doi:10.1111/j.1468-2982.2008.01677.x 22. Cao Y, Welch KM, Aurora S, Vikingstad EM (1999) Functional MRI-BOLD of visually triggered headache in patients with migraine. Arch Neurol 56 (5):548-554 23. Cao Y, Aurora SK, Nagesh V, Patel SC, Welch KM (2002) Functional MRIBOLD of brainstem structures during visually triggered migraine. Neurology 59 (1):72-78

24. Hadjikhani N, Sanchez Del Rio M, Wu O, Schwartz D, Bakker D, Fischl B, Kwong KK, Cutrer FM, Rosen BR, Tootell RB, Sorensen AG, Moskowitz MA (2001) Mechanisms of migraine aura revealed by functional MRI in human visual cortex. Proceedings of the National Academy of Sciences of the United States of America 98 (8):4687-4692. doi:10.1073/pnas.071582498

25. Bramanti P, Grugno R, Vitetta A, Di Bella P, Muscara N, Nappi G (2005) Migraine with and without aura: electrophysiological and functional neuroimaging evidence. Functional neurology 20 (1):29-32

26. Datta R, Aguirre GK, Hu S, Detre JA, Cucchiara B (2013) Interictal cortical hyperresponsiveness in migraine is directly related to the presence of aura. Cephalalgia 33 (6):365-374. doi:10.1177/0333102412474503

27. Vincent M, Pedra E, Mourao-Miranda J, Bramati IE, Henrique AR, Moll J (2003) Enhanced interictal responsiveness of the migraineous visual cortex to incongruent bar stimulation: a functional MRI visual activation study. Cephalalgia 23 (9):860-868

28. Tessitore A, Russo A, Esposito F, Giordano A, Taglialatela G, De Micco R, Cirillo M, Conte F, d'Onofrio F, Cirillo S, Tedeschi G (2011) Interictal cortical reorganization in episodic migraine without aura: an event-related fMRI study during parametric trigeminal nociceptive stimulation. Neurological sciences : official journal of the Italian Neurological Society and of the Italian Society of Clinical Neurophysiology 32 Suppl 1:S165-167. doi:10.1007/s10072-011-0537-0

29. Moulton EA, Burstein R, Tully S, Hargreaves R, Becerra L, Borsook D (2008) Interictal dysfunction of a brainstem descending modulatory center in migraine patients. PLoS One 3 (11):e3799. doi:10.1371/journal.pone.0003799 
30. Kim JH, Suh SI, Seol HY, Oh K, Seo WK, Yu SW, Park KW, Koh SB (2008) Regional grey matter changes in patients with migraine: a voxel-based morphometry study. Cephalalgia : an international journal of headache 28 (6):598604. doi:10.1111/j.1468-2982.2008.01550.x

31. Rocca MA, Colombo B, Pagani E, Falini A, Codella M, Scotti G, Comi G, Filippi M (2003) Evidence for cortical functional changes in patients with migraine and white matter abnormalities on conventional and diffusion tensor magnetic resonance imaging. Stroke; a journal of cerebral circulation 34 (3):665-670. doi:10.1161/01.STR.0000057977.06681.11

32. Schmidt-Wilcke T, Ganssbauer S, Neuner T, Bogdahn U, May A (2008) Subtle grey matter changes between migraine patients and healthy controls. Cephalalgia : an international journal of headache 28 (1):1-4. doi:10.1111/j.14682982.2007.01428.x

33. Schmitz N, Admiraal-Behloul F, Arkink EB, Kruit MC, Schoonman GG, Ferrari MD, van Buchem MA (2008) Attack frequency and disease duration as indicators for brain damage in migraine. Headache 48 (7):1044-1055. doi:10.1111/j.15264610.2008.01133.X

34. Valfre W, Rainero I, Bergui M, Pinessi L (2008) Voxel-based morphometry reveals gray matter abnormalities in migraine. Headache 48 (1):109-117. doi:HED723 [pii]

10.1111/j.1526-4610.2007.00723.x

35. Beaulieu C (2002) The basis of anisotropic water diffusion in the nervous system - a technical review. NMR Biomed 15 (7-8):435-455. doi:10.1002/nbm.782 36. Rocca MA, Ceccarelli A, Falini A, Colombo B, Tortorella P, Bernasconi L, Comi G, Scotti G, Filippi M (2006) Brain gray matter changes in migraine patients with T2-visible lesions: a 3-T MRI study. Stroke; a journal of cerebral circulation 37 (7):1765-1770. doi:10.1161/01.STR.0000226589.00599.4d

37. Li XL, Fang YN, Gao QC, Lin EJ, Hu SH, Ren L, Ding MH, Luo BN (2011) A diffusion tensor magnetic resonance imaging study of corpus callosum from adult patients with migraine complicated with depressive/anxious disorder. Headache 51 (2):237-245. doi:10.1111/j.1526-4610.2010.01774.x 
38. Rocca MA, Pagani E, Colombo B, Tortorella P, Falini A, Comi G, Filippi M (2008) Selective diffusion changes of the visual pathways in patients with migraine: a 3-T tractography study. Cephalalgia 28 (10):1061-1068. doi:10.1111/j.14682982.2008.01655.x

39. DaSilva AF, Granziera C, Tuch DS, Snyder J, Vincent M, Hadjikhani N (2007) Interictal alterations of the trigeminal somatosensory pathway and periaqueductal gray matter in migraine. Neuroreport 18 (4):301-305. doi:10.1097/WNR.0b013e32801776bb

40. Granziera C, DaSilva AF, Snyder J, Tuch DS, Hadjikhani N (2006) Anatomical alterations of the visual motion processing network in migraine with and without aura. PLoS medicine 3 (10):e402. doi:10.1371/journal.pmed.0030402

41. Leone M, Bussone G (2009) Pathophysiology of trigeminal autonomic cephalalgias. Lancet Neurol 8 (8):755-764. doi:S1474-4422(09)70133-4 [pii] $10.1016 / \mathrm{S} 1474-4422(09) 70133-4$

42. Kudrow L (1980.) Cluster headache: mechanisms and management. Oxford University Press edn., London

43. May A, Bahra A, Buchel C, Frackowiak RS, Goadsby PJ (1998) Hypothalamic activation in cluster headache attacks. Lancet 352 (9124):275-278. doi:S01406736(98)02470-2 [pii] 10.1016/S0140-6736(98)02470-2

44. Sprenger T, Boecker H, Tolle TR, Bussone G, May A, Leone M (2004) Specific hypothalamic activation during a spontaneous cluster headache attack. Neurology $62(3): 516-517$

45. May A, Leone M, Boecker H, Sprenger T, Juergens T, Bussone G, Tolle TR (2006) Hypothalamic deep brain stimulation in positron emission tomography. J Neurosci 26 (13):3589-3593. doi:26/13/3589 [pii]

10.1523/JNEUROSCI.4609-05.2006

46. Rocca MA, Valsasina P, Absinta M, Colombo B, Barcella V, Falini A, Comi G, Filippi M (2010) Central nervous system dysregulation extends beyond the painmatrix network in cluster headache. Cephalalgia 30 (11):1383-1391. doi:0333102410365164 [pii] 10.1177/0333102410365164 
47. Absinta M, Rocca MA, Colombo B, Falini A, Comi G, Filippi M (2012) Selective decreased grey matter volume of the pain-matrix network in cluster headache. Cephalalgia : an international journal of headache 32 (2):109-115. doi:10.1177/0333102411431334

48. Szabo N, Kincses ZT, Pardutz A, Tajti J, Szok D, Tuka B, Kiraly A, Babos M, Voros E, Bomboi G, Orzi F, Vecsei L (2012) White matter microstructural alterations in migraine: a diffusion-weighted MRI study. Pain 153 (3):651-656. doi:S0304-3959(11)00727-5 [pii]

10.1016/j.pain.2011.11.029

49. Teepker M, Menzler K, Belke M, Heverhagen JT, Voelker M, Mylius V, Oertel WH, Rosenow F, Knake S (2012) Diffusion tensor imaging in episodic cluster headache. Headache 52 (2):274-282. doi:10.1111/j.1526-4610.2011.02000.x

50. Lipton RB, Stewart WF (1997) Prevalence and impact of migraine. Neurol Clin $15(1): 1-13$

51. Hamilton M (1960) A rating scale for depression. J Neurol Neurosurg Psychiatry 23:56-62

52. Jenkinson M, Smith S (2001) A global optimisation method for robust affine registration of brain images. Medical image analysis 5 (2):143-156

53. Leemans A, Jones DK (2009) The B-matrix must be rotated when correcting for subject motion in DTI data. Magnetic resonance in medicine : official journal of the Society of Magnetic Resonance in Medicine / Society of Magnetic Resonance in Medicine 61 (6):1336-1349. doi:10.1002/mrm.21890

54. Smith SM, Jenkinson M, Johansen-Berg H, Rueckert D, Nichols TE, Mackay CE, Watkins KE, Ciccarelli O, Cader MZ, Matthews PM, Behrens TE (2006) Tractbased spatial statistics: voxelwise analysis of multi-subject diffusion data. Neuroimage 31 (4):1487-1505. doi:10.1016/j.neuroimage.2006.02.024

55. Smith SM, Jenkinson M, Woolrich MW, Beckmann CF, Behrens TE, JohansenBerg H, Bannister PR, De Luca M, Drobnjak I, Flitney DE, Niazy RK, Saunders J, Vickers J, Zhang Y, De Stefano N, Brady JM, Matthews PM (2004) Advances in functional and structural MR image analysis and implementation as FSL. NeuroImage 23 Suppl 1:S208-219. doi:10.1016/j.neuroimage.2004.07.051 
56. Andersson JLR. JM, Smith S. (2007) Non-linear optimisation: FMRIB technical report. Oxford, UK: FMRIB; . Oxford, UK: FMRIB

57. Rueckert D, Sonoda LI, Hayes C, Hill DL, Leach MO, Hawkes DJ (1999) Nonrigid registration using free-form deformations: application to breast MR images. IEEE transactions on medical imaging 18 (8):712-721. doi:10.1109/42.796284

58. Nichols TE, Holmes AP (2002) Nonparametric permutation tests for functional neuroimaging: a primer with examples. Human brain mapping 15 (1):1-25

59. Behrens TE, Berg HJ, Jbabdi S, Rushworth MF, Woolrich MW (2007) Probabilistic diffusion tractography with multiple fibre orientations: What can we gain? Neuroimage 34 (1):144-155. doi:10.1016/j.neuroimage.2006.09.018

60. Smith SM, Nichols TE (2009) Threshold-free cluster enhancement: addressing problems of smoothing, threshold dependence and localisation in cluster inference. NeuroImage 44 (1):83-98. doi:10.1016/j.neuroimage.2008.03.061

61. Seghier ML (2008) Laterality index in functional MRI: methodological issues. Magn Reson Imaging 26 (5):594-601. doi:S0730-725X(07)00437-7 [pii] 10.1016/j.mri.2007.10.010

62. Patenaude B, Smith SM, Kennedy DN, Jenkinson M (2011) A Bayesian model of shape and appearance for subcortical brain segmentation. Neuroimage 56 (3):907-922. doi:10.1016/j.neuroimage.2011.02.046

63. Zhang Y, Brady M, Smith S (2001) Segmentation of brain MR images through a hidden Markov random field model and the expectation-maximization algorithm. IEEE transactions on medical imaging 20 (1):45-57. doi:10.1109/42.906424

64. Jin C, Yuan K, Zhao L, Zhao L, Yu D, von Deneen KM, Zhang M, Qin W, Sun W, Tian J (2013) Structural and functional abnormalities in migraine patients without aura. NMR Biomed 26 (1):58-64. doi:10.1002/nbm.2819

65. Schmitz N, Arkink EB, Mulder M, Rubia K, Admiraal-Behloul F, Schoonman GG, Kruit MC, Ferrari MD, van Buchem MA (2008) Frontal lobe structure and executive function in migraine patients. Neurosci Lett 440 (2):92-96. doi:10.1016/j.neulet.2008.05.033

66. Apkarian AV, Sosa Y, Sonty S, Levy RM, Harden RN, Parrish TB, Gitelman DR (2004) Chronic back pain is associated with decreased prefrontal and thalamic 
gray matter density. The Journal of neuroscience : the official journal of the Society for Neuroscience 24 (46):10410-10415. doi:10.1523/JNEUROSCI.2541-04.2004 67. Kuchinad A, Schweinhardt P, Seminowicz DA, Wood PB, Chizh BA, Bushnell MC (2007) Accelerated brain gray matter loss in fibromyalgia patients: premature aging of the brain? J Neurosci 27 (15):4004-4007. doi:10.1523/JNEUROSCI.009807.2007

68. Lutz J, Jager L, de Quervain D, Krauseneck T, Padberg F, Wichnalek M, Beyer A, Stahl R, Zirngibl B, Morhard D, Reiser M, Schelling G (2008) White and gray matter abnormalities in the brain of patients with fibromyalgia: a diffusion-tensor and volumetric imaging study. Arthritis Rheum 58 (12):3960-3969. doi:10.1002/art.24070

69. Baliki MN, Chialvo DR, Geha PY, Levy RM, Harden RN, Parrish TB, Apkarian AV (2006) Chronic pain and the emotional brain: specific brain activity associated with spontaneous fluctuations of intensity of chronic back pain. J Neurosci 26 (47):12165-12173. doi:10.1523/JNEUROSCI.3576-06.2006

70. Farmer MA, Chanda ML, Parks EL, Baliki MN, Apkarian AV, Schaeffer AJ (2011) Brain functional and anatomical changes in chronic prostatitis/chronic pelvic pain syndrome. The Journal of urology 186 (1):117-124. doi:10.1016/j.juro.2011.03.027

71. Geha PY, Baliki MN, Harden RN, Bauer WR, Parrish TB, Apkarian AV (2008) The brain in chronic CRPS pain: abnormal gray-white matter interactions in emotional and autonomic regions. Neuron 60 (4):570-581. doi:10.1016/j.neuron.2008.08.022

72. Burstein R, Jakubowski M, Garcia-Nicas E, Kainz V, Bajwa Z, Hargreaves R, Becerra L, Borsook D (2010) Thalamic sensitization transforms localized pain into widespread allodynia. Ann Neurol 68 (1):81-91. doi:10.1002/ana.21994

73. Gu T, Ma XX, Xu YH, Xiu JJ, Li CF (2008) Metabolite concentration ratios in thalami of patients with migraine and trigeminal neuralgia measured with 1H-MRS. Neurological research 30 (3):229-233. doi:10.1179/016164107X235473

74. Bahra A, Matharu MS, Buchel C, Frackowiak RS, Goadsby PJ (2001) Brainstem activation specific to migraine headache. Lancet 357 (9261):1016-1017 
75. Kobari M, Meyer JS, Ichijo M, Imai A, Oravez WT (1989) Hyperperfusion of cerebral cortex, thalamus and basal ganglia during spontaneously occurring migraine headaches. Headache 29 (5):282-289

76. Mathew NT (1999) Naratriptan: a review. Expert opinion on investigational drugs 8 (5):687-695. doi:10.1517/13543784.8.5.687

77. Shields KG, Goadsby PJ (2006) Serotonin receptors modulate trigeminovascular responses in ventroposteromedial nucleus of thalamus: a migraine target? Neurobiol Dis 23 (3):491-501. doi:10.1016/j.nbd.2006.04.003

78. Moayedi M, Weissman-Fogel I, Crawley AP, Goldberg MB, Freeman BV, Tenenbaum HC, Davis KD (2011) Contribution of chronic pain and neuroticism to abnormal forebrain gray matter in patients with temporomandibular disorder. NeuroImage 55 (1):277-286. doi:10.1016/j.neuroimage.2010.12.013

79. Younger JW, Shen YF, Goddard G, Mackey SC (2010) Chronic myofascial temporomandibular pain is associated with neural abnormalities in the trigeminal and limbic systems. Pain 149 (2):222-228. doi:10.1016/j.pain.2010.01.006

80. Gustin SM, Peck CC, Wilcox SL, Nash PG, Murray GM, Henderson LA (2011) Different pain, different brain: thalamic anatomy in neuropathic and nonneuropathic chronic pain syndromes. The Journal of neuroscience : the official journal of the Society for Neuroscience 31 (16):5956-5964. doi:10.1523/JNEUROSCI.5980-10.2011

81. Obermann M, Rodriguez-Raecke R, Naegel S, Holle D, Mueller D, Yoon MS, Theysohn N, Blex S, Diener HC, Katsarava Z (2013) Gray matter volume reduction reflects chronic pain in trigeminal neuralgia. Neuroimage 74:352-358. doi:10.1016/j.neuroimage.2013.02.029

82. Draganski B, Moser T, Lummel N, Ganssbauer S, Bogdahn U, Haas F, May A (2006) Decrease of thalamic gray matter following limb amputation. NeuroImage 31 (3):951-957. doi:10.1016/j.neuroimage.2006.01.018

83. Wu Q, Inman RD, Davis KD (2013) Neuropathic pain in ankylosing spondylitis: a psychophysics and brain imaging study. Arthritis and rheumatism 65 (6):1494-1503. doi:10.1002/art.37920 
84. Knotkova H, Pappagallo M (2007) Imaging intracranial plasma extravasation in a migraine patient: a case report. Pain medicine 8 (4):383-387. doi:10.1111/j.15264637.2006.00197.x

85. Cui Y, Takashima T, Takashima-Hirano M, Wada Y, Shukuri M, Tamura Y, Doi H, Onoe H, Kataoka Y, Watanabe Y (2009) 11C-PK11195 PET for the in vivo evaluation of neuroinflammation in the rat brain after cortical spreading depression. J Nucl Med 50 (11):1904-1911. doi:10.2967/jnumed.109.066498

86. Arnold G, Reuter U, Kinze S, Wolf T, Einhaupl KM (1998) Migraine with aura shows gadolinium enhancement which is reversed following prophylactic treatment. Cephalalgia : an international journal of headache 18 (9):644-646

87. Gursoy-Ozdemir Y, Qiu J, Matsuoka N, Bolay H, Bermpohl D, Jin H, Wang X, Rosenberg GA, Lo EH, Moskowitz MA (2004) Cortical spreading depression activates and upregulates MMP-9. J Clin Invest 113 (10):1447-1455. doi:10.1172/JCI21227

88. Gupta VK (2009) CSD, BBB and MMP-9 elevations: animal experiments versus clinical phenomena in migraine. Expert review of neurotherapeutics 9 (11):1595-1614. doi:10.1586/ern.09.103

89. Bernecker C, Pailer S, Kieslinger P, Horejsi R, Moller R, Lechner A, WallnerBlazek M, Weiss S, Fazekas F, Truschnig-Wilders M, Gruber HJ (2011) Increased matrix metalloproteinase activity is associated with migraine and migraine-related metabolic dysfunctions. Eur J Neurol 18 (4):571-576. doi:10.1111/j.1468$1331.2010 .03205 . x$

90. Yilmaz N, Karaali K, Ozdem S, Turkay M, Unal A, Dora B (2011) Elevated S100B and neuron specific enolase levels in patients with migraine-without aura: evidence for neurodegeneration? Cellular and molecular neurobiology 31 (4):579585. doi:10.1007/s10571-011-9651-z

91. Della Nave R, Ginestroni A, Tessa C, Giannelli M, Piacentini S, Filippi M, Mascalchi M (2010) Regional distribution and clinical correlates of white matter structural damage in Huntington disease: a tract-based spatial statistics study. AJNR Am J Neuroradiol 31 (9):1675-1681. doi:10.3174/ajnr.A2128

92. Ibarretxe-Bilbao N, Junque C, Marti MJ, Valldeoriola F, Vendrell P, Bargallo N, Zarei M, Tolosa E (2010) Olfactory impairment in Parkinson's disease and white 
matter abnormalities in central olfactory areas: A voxel-based diffusion tensor imaging study. Mov Disord 25 (12):1888-1894. doi:10.1002/mds.23208

93. Kim JH, Budde MD, Liang HF, Klein RS, Russell JH, Cross AH, Song SK (2006) Detecting axon damage in spinal cord from a mouse model of multiple sclerosis. Neurobiology of disease 21 (3):626-632. doi:10.1016/j.nbd.2005.09.009

94. Sun SW, Liang HF, Trinkaus K, Cross AH, Armstrong RC, Song SK (2006) Noninvasive detection of cuprizone induced axonal damage and demyelination in the mouse corpus callosum. Magn Reson Med 55 (2):302-308. doi:10.1002/mrm.20774

95. Pierpaoli C, Barnett A, Pajevic S, Chen R, Penix LR, Virta A, Basser P (2001) Water diffusion changes in Wallerian degeneration and their dependence on white matter architecture. Neuroimage $13 \quad(6 \quad$ Pt 1$): 1174-1185$. doi:10.1006/nimg.2001.0765

96. Cooney BS, Grossman RI, Farber RE, Goin JE, Galetta SL (1996) Frequency of magnetic resonance imaging abnormalities in patients with migraine. Headache 36 (10):616-621

97. Kruit MC, Launer LJ, Overbosch J, van Buchem MA, Ferrari MD (2009) Iron accumulation in deep brain nuclei in migraine: a population-based magnetic resonance imaging study. Cephalalgia : an international journal of headache 29 (3):351-359. doi:10.1111/j.1468-2982.2008.01723.x

98. Rozen TD (2007) Acute treatment for migraine headache. Minerva medica 98 (1):43-52

99. Rozen TD (2007) Vanishing cerebellar infarcts in a migraine patient. Cephalalgia : an international journal of headache 27 (6):557-560. doi:10.1111/j.1468-2982.2007.01317.x

100. Turkoglu R, Tuzun E, Icoz S, Birisik O, Erdag E, Kurtuncu M, Akman-Demir G (2011) Antineuronal antibodies in migraine patients with white matter lesions. The International journal of neuroscience 121 (1):33-36. doi:10.3109/00207454.2010.524331

101. Boyke J, Driemeyer J, Gaser C, Buchel C, May A (2008) Training-induced brain structure changes in the elderly. J Neurosci 28 (28):7031-7035. doi:10.1523/JNEUROSCI.0742-08.2008 
102. Draganski B, Gaser C, Busch V, Schuierer G, Bogdahn U, May A (2004) Neuroplasticity: changes in grey matter induced by training. Nature 427 (6972):311-312. doi:10.1038/427311a

103. Scholz J, Klingemann I, Moser A (2004) Increased systemic levels of norsalsolinol derivatives are induced by levodopa treatment and do not represent biological markers of Parkinson's disease. J Neurol Neurosurg Psychiatry 75 (4):634-636

104. Teutsch S, Herken W, Bingel U, Schoell E, May A (2008) Changes in brain gray matter due to repetitive painful stimulation. NeuroImage 42 (2):845-849. doi:10.1016/j.neuroimage.2008.05.044

105. Afra J, Proietti Cecchini A, Sandor PS, Schoenen J (2000) Comparison of visual and auditory evoked cortical potentials in migraine patients between attacks. Clinical neurophysiology : official journal of the International Federation of Clinical Neurophysiology 111 (6):1124-1129

106. Antal A, Temme J, Nitsche MA, Varga ET, Lang N, Paulus W (2005) Altered motion perception in migraineurs: evidence for interictal cortical hyperexcitability. Cephalalgia : an international journal of headache 25 (10):788-794. doi:10.1111/j.1468-2982.2005.00949.x

107. Aurora SK, Ahmad BK, Welch KM, Bhardhwaj P, Ramadan NM (1998) Transcranial magnetic stimulation confirms hyperexcitability of occipital cortex in migraine. Neurology 50 (4):1111-1114

108. Chadaide Z, Arlt S, Antal A, Nitsche MA, Lang N, Paulus W (2007) Transcranial direct current stimulation reveals inhibitory deficiency in migraine. Cephalalgia : an international journal of headache 27 (7):833-839. doi:10.1111/j.1468-2982.2007.01337.x

109. Gawel M, Connolly JF, Rose FC (1983) Migraine patients exhibit abnormalities in the visual evoked potential. Headache 23 (2):49-52

110. Dehbandi S, Speckmann EJ, Pape HC, Gorji A (2008) Cortical spreading depression modulates synaptic transmission of the rat lateral amygdala. Eur $\mathbf{J}$ Neurosci 27 (8):2057-2065. doi:10.1111/j.1460-9568.2008.06188.x 
111. Haghir H, Kovac S, Speckmann EJ, Zilles K, Gorji A (2009) Patterns of neurotransmitter receptor distributions following cortical spreading depression. Neuroscience 163 (4):1340-1352. doi:10.1016/j.neuroscience.2009.07.067

112. Sas K, Pardutz A, Toldi J, Vecsei L (2010) Dementia, stroke and migraine-some common pathological mechanisms. J Neurol Sci 299 (1-2):55-65. doi:10.1016/j.jns.2010.08.001

113. Welch KM, Nagesh V, Aurora SK, Gelman N (2001) Periaqueductal gray matter dysfunction in migraine: cause or the burden of illness? Headache 41 (7):629-637

114. Levy M, Faas GC, Saggau P, Craigen WJ, Sweatt JD (2003) Mitochondrial regulation of synaptic plasticity in the hippocampus. J Biol Chem 278 (20):1772717734. doi:10.1074/jbc.M212878200

115. Volkmar FR, Greenough WT (1972) Rearing complexity affects branching of dendrites in the visual cortex of the rat. Science 176 (4042):1445-1447

116. Turner AM, Greenough WT (1985) Differential rearing effects on rat visual cortex synapses. I. Synaptic and neuronal density and synapses per neuron. Brain Res 329 (1-2):195-203. doi:0006-8993(85)90525-6 [pii]

117. Yanamoto H, Miyamoto S, Tohnai N, Nagata I, Xue JH, Nakano Y, Nakajo Y, Kikuchi H (2005) Induced spreading depression activates persistent neurogenesis in the subventricular zone, generating cells with markers for divided and early committed neurons in the caudate putamen and cortex. Stroke 36 (7):1544-1550. doi:01.STR.0000169903.09253.c7 [pii]

10.1161/01.STR.0000169903.09253.c7

118. Davis KD, Pope G, Chen J, Kwan CL, Crawley AP, Diamant NE (2008) Cortical thinning in IBS: implications for homeostatic, attention, and pain processing. Neurology 70 (2):153-154. doi:10.1212/01.wnl.0000295509.30630.10 119. Gerstner G, Ichesco E, Quintero A, Schmidt-Wilcke T (2011) Changes in regional gray and white matter volume in patients with myofascial-type temporomandibular disorders: a voxel-based morphometry study. Journal of orofacial pain 25 (2):99-106 
120. Scholz J, Klein MC, Behrens TE, Johansen-Berg H (2009) Training induces changes in white-matter architecture. Nature neuroscience 12 (11):1370-1371. doi:10.1038/nn.2412

121. May A (2009) Morphing voxels: the hype around structural imaging of headache patients. Brain 132 (Pt 6):1419-1425. doi:10.1093/brain/awp116

122. Woolf CJ, Salter MW (2000) Neuronal plasticity: increasing the gain in pain. Science 288 (5472):1765-1769

123. Hsu MC, Harris RE, Sundgren PC, Welsh RC, Fernandes CR, Clauw DJ, Williams DA (2009) No consistent difference in gray matter volume between individuals with fibromyalgia and age-matched healthy subjects when controlling for affective disorder. Pain 143 (3):262-267. doi:10.1016/j.pain.2009.03.017

124. Blankstein U, Chen J, Diamant NE, Davis KD (2010) Altered brain structure in irritable bowel syndrome: potential contributions of pre-existing and disease$\begin{array}{lllll}\text { driven } & \text { factors. } & \text { Gastroenterology } & 138 & \text { (5):1783-1789. }\end{array}$ doi:10.1053/j.gastro.2009.12.043

125. Hadjipavlou G, Dunckley P, Behrens TE, Tracey I (2006) Determining anatomical connectivities between cortical and brainstem pain processing regions in humans: a diffusion tensor imaging study in healthy controls. Pain 123 (1-2):169178. doi:S0304-3959(06)00118-7 [pii]

10.1016/j.pain.2006.02.027

126. Sillery E, Bittar RG, Robson MD, Behrens TE, Stein J, Aziz TZ, JohansenBerg H (2005) Connectivity of the human periventricular-periaqueductal gray

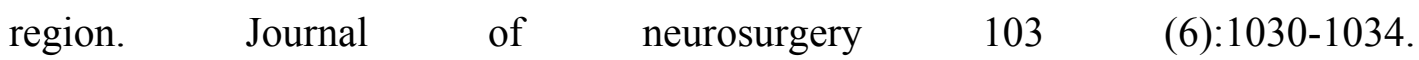
doi:10.3171/jns.2005.103.6.1030

127. Mainero C, Boshyan J, Hadjikhani N Altered functional magnetic resonance imaging resting-state connectivity in periaqueductal gray networks in migraine. Ann Neurol 70 (5):838-845. doi:10.1002/ana.22537

128. Lipton RB, Bigal ME, Ashina S, Burstein R, Silberstein S, Reed ML, Serrano D, Stewart WF (2008) Cutaneous allodynia in the migraine population. Ann Neurol 63 (2):148-158. doi:10.1002/ana.21211 
129. Strassman AM, Raymond SA, Burstein R (1996) Sensitization of meningeal sensory neurons and the origin of headaches. Nature 384 (6609):560-564. doi:10.1038/384560a0

130. Chiaia NL, Rhoades RW, Fish SE, Killackey HP (1991) Thalamic processing of vibrissal information in the rat: II. Morphological and functional properties of medial ventral posterior nucleus and posterior nucleus neurons. J Comp Neurol 314 (2):217-236. doi:10.1002/cne.903140203

131. Zhan L, Leow AD, Jahanshad N, Chiang MC, Barysheva M, Lee AD, Toga AW, McMahon KL, de Zubicaray GI, Wright MJ, Thompson PM How does angular resolution affect diffusion imaging measures? Neuroimage 49 (2):13571371. doi:S1053-8119(09)01056-8 [pii]

10.1016/j.neuroimage.2009.09.057

132. Sun SW, Liang HF, Cross AH, Song SK (2008) Evolving Wallerian degeneration after transient retinal ischemia in mice characterized by diffusion tensor imaging. NeuroImage 40 (1):1-10. doi:10.1016/j.neuroimage.2007.11.049

133. Beaulieu C, Allen PS (1994) Determinants of anisotropic water diffusion in nerves. Magnetic resonance in medicine : official journal of the Society of Magnetic Resonance in Medicine / Society of Magnetic Resonance in Medicine 31 (4):394400

134. Martelletti P, Granata M, Giacovazzo M (1993) Serum interleukin-1 beta is increased in cluster headache. Cephalalgia : an international journal of headache 13 (5):343-345; discussion 307-348

135. Steinberg A, Axelsson R, Idestrom L, Muller S, Nilsson Remahl AI (2012) White blood cell SPECT during active period of cluster headache and in remission. European journal of neurology : the official journal of the European Federation of Neurological Societies 19 (2):220-225. doi:10.1111/j.1468-1331.2011.03456.x

136. Zhang J, Jones M, DeBoy CA, Reich DS, Farrell JA, Hoffman PN, Griffin JW, Sheikh KA, Miller MI, Mori S, Calabresi PA (2009) Diffusion tensor magnetic resonance imaging of Wallerian degeneration in rat spinal cord after dorsal root axotomy. The Journal of neuroscience : the official journal of the Society for Neuroscience 29 (10):3160-3171. doi:10.1523/JNEUROSCI.3941-08.2009 
137. Mac Donald CL, Dikranian K, Song SK, Bayly PV, Holtzman DM, Brody DL (2007) Detection of traumatic axonal injury with diffusion tensor imaging in a mouse model of traumatic brain injury. Experimental neurology 205 (1):116-131. doi:10.1016/j.expneurol.2007.01.035

138. Zhang J, Aggarwal M, Mori S (2012) Structural insights into the rodent CNS via diffusion tensor imaging. Trends in neurosciences 35 (7):412-421. doi:10.1016/j.tins.2012.04.010

139. Wozniak JR, Lim KO (2006) Advances in white matter imaging: a review of in vivo magnetic resonance methodologies and their applicability to the study of development and aging. Neurosci Biobehav Rev 30 (6):762-774. doi:S01497634(06)00047-9 [pii]

10.1016/j.neubiorev.2006.06.003

140. Di Piero V, Fiacco F, Tombari D, Pantano P (1997) Tonic pain: a SPET study in normal subjects and cluster headache patients. Pain 70 (2-3):185-191

141. Morelli N, Gori S, Cafforio G, Gallerini S, Baldacci F, Orlandi G, Murri L (2005) Prevalence of right-to-left shunt in patients with cluster headache. J Headache Pain 6 (4):244-246. doi:10.1007/s10194-005-0197-7

142. Morelli N, Pesaresi I, Cafforio G, Maluccio MR, Gori S, Di Salle F, Murri L (2009) Functional magnetic resonance imaging in episodic cluster headache. J Headache Pain 10 (1):11-14. doi:10.1007/s10194-008-0085-Z

143. Seifert CL, Magon S, Staehle K, Zimmer C, Foerschler A, Radue EW, Pfaffenrath V, Tolle TR, Sprenger T (2012) A case-control study on cortical thickness in episodic cluster headache. Headache 52 (9):1362-1368. doi:10.1111/j.1526-4610.2012.02217.x

144. May A, Bahra A, Buchel C, Frackowiak RS, Goadsby PJ (2000) PET and MRA findings in cluster headache and MRA in experimental pain. Neurology 55 (9):1328-1335

145. Evers S (2005) Cognitive processing in cluster headache. Current pain and headache reports 9 (2):109-112

146. Rist PM, Kang JH, Buring JE, Glymour MM, Grodstein F, Kurth T (2012) Migraine and cognitive decline among women: prospective cohort study. Bmj 345:e5027. doi:10.1136/bmj.e5027 
147. Qiu EC, Yu SY, Liu RZ, Wang Y, Ma L, Tian LX (2012) Altered regional homogeneity in spontaneous cluster headache attacks: a resting-state functional magnetic resonance imaging study. Chin Med J (Engl) 125 (4):705-709 148. Schwedt TJ, Schlaggar BL, Mar S, Nolan T, Coalson RS, Nardos B, Benzinger T, Larson-Prior LJ (2013) Atypical resting-state functional connectivity of affective pain regions in chronic migraine. Headache 53 (5):737-751. doi:10.1111/head.12081

149. Yu D, Yuan K, Zhao L, Zhao L, Dong M, Liu P, Wang G, Liu J, Sun J, Zhou G, von Deneen KM, Liang F, Qin W, Tian J (2012) Regional homogeneity abnormalities in patients with interictal migraine without aura: a resting-state study. NMR in biomedicine 25 (5):806-812. doi:10.1002/nbm.1796 